\title{
Does Culture Affect Unemployment?** EvidenCE FROM THE Röstigraben
}

\author{
Beatrix Brügger, University of Lausanne \\ Rafael Lalive, University of Lausanne and CEPR \\ Josef Zweimüller, University of Zurich and CEPR
}

June 22, 2009

\begin{abstract}
This paper studies the role of culture in shaping unemployment outcomes. The empirical analysis is based on local comparisons across a language barrier in Switzerland. This Röstigraben separates cultural groups, but neither labor markets nor political jurisdictions. Local contrasts across the language border identify the role of culture for unemployment. Our findings indicate that differences in culture explain differences in unemployment duration on the order of $20 \%$. Moreover, we find that horizontal transmission of culture is more important than vertical transmission of culture and that culture is about as important as strong changes to the benefit duration.
\end{abstract}

JEL classification: J21, J64, Z10

Keywords: culture, cultural transmission, unemployment duration, regional unemployment.

${ }^{*}$ We are grateful to Richard Berthoud, David Card, Christian Dustmann, Andrea Ichino, Steve Jenkins, Michael Lechner, Guy Michaels, Jean-Baptiste Michau, Javier Ortega, Barbara Petrongolo, Steve Pudney, Steve Pischke, Analia Schlosser, Arthur von Soest, Mathias Thoenig, Rudolf Winter-Ebmer and seminar participants at Athens, Berkeley, Bern, Champex, Engelberg, Essex, Harvard, Houston, IZA, LSE, PSE, Tel Aviv, UCL, and Zurich for helpful comments. Andreas Steinhauer provided excellent research assistance. We acknowledge funding from the Swiss National Science Foundation (Grant No. 100012-120356/1). We would also like to thank Jonathan Gast at the Swiss State Secretariat for Economic Affairs for help concerning the data and information on institutional details. Addresses: Beatrix Brügger, University of Lausanne, Faculty of Business and Economics, Internef, CH1015 Lausanne-Dorigny, beatrix.bruegger@unil.ch. Rafael Lalive, University of Lausanne, Faculty of Business and Economics, CH-1015 Lausanne-Dorigny, rafael.lalive@unil.ch. Rafael Lalive is also affiliated with CESifo, IFAU, and IZA. Josef Zweimüller, University of Zurich, Department of Economics, Mühlebachstrasse 86, CH-8008 Zürich, zweim@iew.uzh.ch. Josef Zweimüller is also affiliated with CESifo, and IZA 


\section{Introduction}

Economists have long been interested in understanding the role of culture in shaping economic outcomes because there is tremendous spatial variation in beliefs and values across countries and regions. For instance, Alexis de Tocqueville's (1848) account of his 1831/1832 voyage to the United States of America documents that he was fascinated by the differences in the core values that shape the ways democracies work. But only until recently, Guiso et al. (2006) have transformed culture from a vacuous concept to one with clear and testable predictions. Clarifying that culture refers to the set of beliefs and values shared within religious, ethnic or social groups with separate identities, this line of research has contributed strongly to our understanding of the slow moving aspect of culture - the role of values and norms transmitted from religious or political authorities or parents to their children (Guiso et al., 2006, Tabellini, 2005, Fernández, 2007).

Yet, it is to date not clear to what extent cultural differences in work norms and values affect unemployment. While labor economics has contributed to understanding the role of institutions in shaping equilibrium unemployment outcomes (Nickell and Layard, 1999), this literature can not rationalize one of the most important facts in unemployment research - the existence of strong differences in unemployment across regions of the same country (OECD 2005).

In this paper, we study how unemployment is affected by differences in culturally determined attitudes towards work within a narrowly defined geographic area. Our focus is Switzerland, a country that is divided into two culturally distinct language regions: "Latin-speaking" (i.e. French, Italian, or Romansh) regions and "German-speaking" regions. These regions are characterized by strong differences in residents' attitudes towards the importance of work. For instance, $78 \%$ of people living in the German speaking part of Switzerland state that "I would work even if I did not need the money", yet only $50 \%$ of French or Italian- speaking survey respondents agree with this statement. ${ }^{1}$ What is more, these differences in attitudes towards work also translate into differences in actual voting behavior. Voters living in the Latin-speaking regions tend to support limits to weekly working time much more strongly than people living in the German-speaking regions of the country.

We explore to which extent these cultural differences in work attitudes affect unemployment. The key idea is to focus on unemployment differences at the border between language regions. It is widely recognized that Swiss language areas are associated with specific cultural traits and that the country is divided by an important cultural border: the Röstigraben. This term referring to the German-Swiss way to prepare potatoes, Rösti - has become a metaphor for the general cultural divide within the country. ${ }^{2}$ The cliché is that German-Swiss are hard working, historically used to spartan living conditions, being proud of their independence and deriving

\footnotetext{
${ }^{1}$ These figures are from a 1998 survey on work attitudes conducted by University of Berne (Diekmann et al. 1998).

${ }^{2}$ Many commentators have written about the differences between these two cultural areas and speculated about the implications of this cultural divide for the political and socio-economic stability of the country. For an interesting recent contribution summarizing and taking stock of the debate, see Büchi (2003).
} 
their identity from the founding myth of the Swiss federation. In contrast, Latin-Swiss are bonvivants enjoying the fruits of their temperate climate and, being a minority in the own country, are much more outward-oriented (towards France and Italy, and the EU as a whole). ${ }^{3}$

There are three features of this language border which are of particular interest in the present context. First, the dominant native language changes sharply at the Röstigraben. Within a geographical distance of 5 kilometers, the fraction of Latin speaking Swiss residents falls from more than 90 percent to less than 5 percent (and vice versa for German native speakers). Since language is central to the spreading of beliefs and norms and determines an individual's social identity, the language barrier represents a sharp cultural barrier. Second, important segments of the language border do not coincide with the borders of political jurisdictions, i.e. cantons. This means we can separate effects of culture from effects of institutions. Third, an in-depth analysis of key determinants of job search success suggests that these determinants do not vary at the language border to an extent that could rationalize observed differences in unemployment. This suggests that the language border is permeable and markets are integrated. These three aspects allow separating the effects of culture on unemployment from the effects of institutions and markets on unemployment.

To analyze language-border differentials in unemployment outcomes we use data from two sources. The first data source comprises the universe of individuals entering unemployment over the period 1998-2003. The main focus of our analysis is on Swiss men in the age group 25-60 - more than 170,000 unemployment spells. A nice feature of this data set is that it provides information on how the post-unemployment job was found: whether an individual found a new job by own initiative or by placement via the local labor office. This information is very helpful in understanding the relative importance of individual search effort as a determinant of observed unemployment differences at the language border. The second data source provides information on all residents' employment status in the year 2000. This data source allows discussing the role of culture in shaping other margins of labor supply - labor force participation and weekly hours worked.

Our empirical results suggest that culture affects unemployment strongly. The first main finding indicates a robust difference in unemployment durations at the language border. Individuals living in Latin-speaking border communities - facing observationally identical labor markets - tend to leave unemployment 7 weeks later than their neighbors living in German speaking communities. This is a very large effect comparable to the impact of a drastic change in the unemployment insurance system. ${ }^{4}$ Observed unemployment differences at the Röstigraben

\footnotetext{
${ }^{3}$ Historically, Switzerland was founded by the German-speaking cantons Schwyz, Uri and Nidwalden, located in the center of the country and was successively enlarged by the entrance of Berne, Zurich, Lucerne and other cities of the German speaking part. Until the French invasion at the turn of the 19th century large parts of French Switzerland were ruled by the German-speaking elites of Berne and Fribourg. In 1848, the new constitution with 26 cantons (of which 4 French speaking, 1 Italian speaking, 3 bilingual (French / German) cantons, and 18 German-speaking cantons) was adopted.

${ }^{4}$ Katz and Meyer (1990) estimate that a 10 week increase in potential benefit duration increases the average duration of unemployment by about 1 week. Hence the difference in unemployment durations generated at the
} 
are unlikely to reflect differences in labor demand on locally segregated labor markets. On the one hand, in communities located close to the language border, a large fraction of residents cross this border when going to work. This suggests that the labor market is highly integrated. On the other hand, we do not see major differences in unemployment durations at the Röstigraben among migrants who neither speak German nor a Latin language. This group of immigrants is subject to the same local labor market conditions but is unlikely to share native residents' attitudes and norms concerning work effort and job search behavior.

Our second main finding concerns the way in which unemployed individuals find a new job. We find that Latin-speaking job seekers are much less likely to find a job on their own initiative and slightly more likely to find a job mediated by the local labor office than German-speaking job seekers. This result provides further support for the claim that differences in local labor market conditions are unlikely to account for observed unemployment outcomes. It also rules out that discrimination by employers against Latin-speaking job seekers is the main explanation for observed unemployment differences. If lack of jobs and/or discrimination were the main drivers, the two exit channels would both account for the observed unemployment differences. In contrast, if unemployment differences are generated by differential values and norms concerning job seekers' adequate search effort, we will see a direct impact on the probability to find a job by own initiative but no negative impact on the rate of job offers mediated by the public employment office.

Our third main finding concerns the relative importance of vertical versus horizontal transmission of culture. To separate these two channels we contrast the role of the individual's native language to the role of the dominant native language of one's community in explaining unemployment duration. An individual's native language is a proxy for the vertical transmission of culture, i.e. values and norms transmitted from parents to their children (conditional on ability to speak the dominant language spoken in the local labor market). In contrast, a community's dominant native language proxies the norms and values prevalent in an individual's place of residence. Our results indicate that cultural attitudes towards work in one's community are more important than individual attitudes. This suggests that the horizontal transmission of cultural values and the impact of attitudes towards work and job search are quantitatively important determinants of unemployment durations.

Our paper is related to a new literature that has begun to analyze the impact of culture on various labor market outcomes. Alesina, Glaeser and Sacerdote (2006) investigate why Americans work so much more than Europeans. They argue European labor market regulations influenced leisure patterns and created a "leisure culture" through a social multiplier (the returns to leisure are higher when more people are taking longer vacations). A model based on such complementarities in leisure performs better in explaining US-European differences in working hours than a model that is based on differences in taxation (Prescott 2004). Fernández and Fogli $(2006,2009)$ find that work (and fertility) behavior of married second-generation im-

Röstigraben to an increase in potential benefit duration by much more than one year! 
migrant women is significantly affected by the country of heritage. This is consistent with the hypothesis that current economic outcomes are affected by the culture of the country of origin. Fernández (2007) shows that attitudes in the country of ancestry towards women's market work and housework have explanatory power for current labor market participation. The particular role of "family culture" on labor market outcomes are investigated in Algan and Cahuc (2005) and Alesina and Giuliano (2007). These studies find that strong family ties reduce labor force participation. Ichino and Maggi (2000) study cultural differences in the propensity to shirk (absenteeism and misconduct) using data from a large Italian bank. A further related strand of the literature has focused on the emergence and support for labor market institutions such as the unemployment insurance system. Algan and Cahuc (2009) argue that cultural differences can explain why some countries implement different mixes of employment protection and unemployment insurance. Lindbeck et al. (2003), and Lindbeck and Nyberg (2006) consider the dynamics of work ethics and how these dynamics interact with the evolution of welfare state provisions. $^{5}$

This paper contributes to the literature in at least three respects. First, this paper provides novel quasi-experimental evidence on the role of culture for unemployment outcomes. Limiting the empirical analysis to a narrowly defined geographic area helps separating the cultural component of unemployment from other relevant explanations for differences in unemployment. Second, we separate the role of vertical and horizontal transmission. In doing so, we complement the results from the epidemiological approach to studying culture (Fernández, 2007) and results from the IV approach to studying the role of culture (Guiso et al. 2006). Both the epidemiological approach and the IV approach do not discuss the relevance of social spillovers of culture - the fast moving aspect of culture. Understanding this is important from an economic point of view. If cultural differences in individual norms and values do not spill over to other individuals, culture will not be able to rationalize much of the variance in regional unemployment. However, if culturally shaped attitudes towards working spill over to other individuals, micro differences in attitudes build up to macro differences in behavior. Third, to our knowledge, our paper provides the first study that assesses the causal impact of culture on unemployment. In this sense we shed light on the role of culture in shaping one of the most important socio-economic outcomes that has not been studied so far.

The remainder of this paper is organized as follows. In the next section we provide background on unemployment and the unemployment insurance in Switzerland as well as on the language regions and their cultural differences. Section 3 presents the identification strategy used, namely the spatial regression discontinuity design, and describes the various data sources

\footnotetext{
${ }^{5}$ Two further strands of the literature are related. A theoretical strand considers the transmission of cultural values from parents to children. See e.g. Bisin and Verdier (2000, 2001, 2004) on marriage and religion, Hauk and Saez Marti (2002) on corruption, Doepke and Zilibotti (2008) on class-specific preferences and the industrial revolution. Other empirical studies have looked at the role of of culture in explaining the demand for redistribution (Alesina and Fuchs-Schündeln 2007), economic performance (Tabellini 2005), or trade (Guiso et al. 2009; Thoenig et al 2009), and horizontal spillovers in unemployment outcomes (Stutzer and Lalive 2004; Clark 2003; Kolm 2005).
} 
that we use in the empirical analysis. Sections 4 to 6 detail our empirical strategy to assess the impact of culture on unemployment, present our main empirical results and provide sensitivity analyzes. Section 7 concludes.

\section{Institutions and Language Regions}

\subsection{Unemployment and unemployment insurance in Switzerland}

One crucial fact, puzzling policy makers and researchers alike, are large and persistent differences in unemployment rates between the German-speaking and the Latin-speaking parts of the country. Figure 1 shows that, during the period 1997-2006, unemployment rates were between 1.5 and 2 times as large in Latin-Swiss as compared to German-Swiss cantons. This difference is to a large extent driven by a longer duration of unemployment spells in Latin-speaking regions. The percentage long-term unemployed - the fraction of individuals being in the unemployment pool since more than a year - has been up to twice as large in Latin-speaking cantons during the period 1997-2006. This suggests that differences in unemployment durations are key to understand differences in unemployment rates between language regions in Switzerland.

Figure 1: Unemployment rates in Latin-speaking versus German-speaking cantons

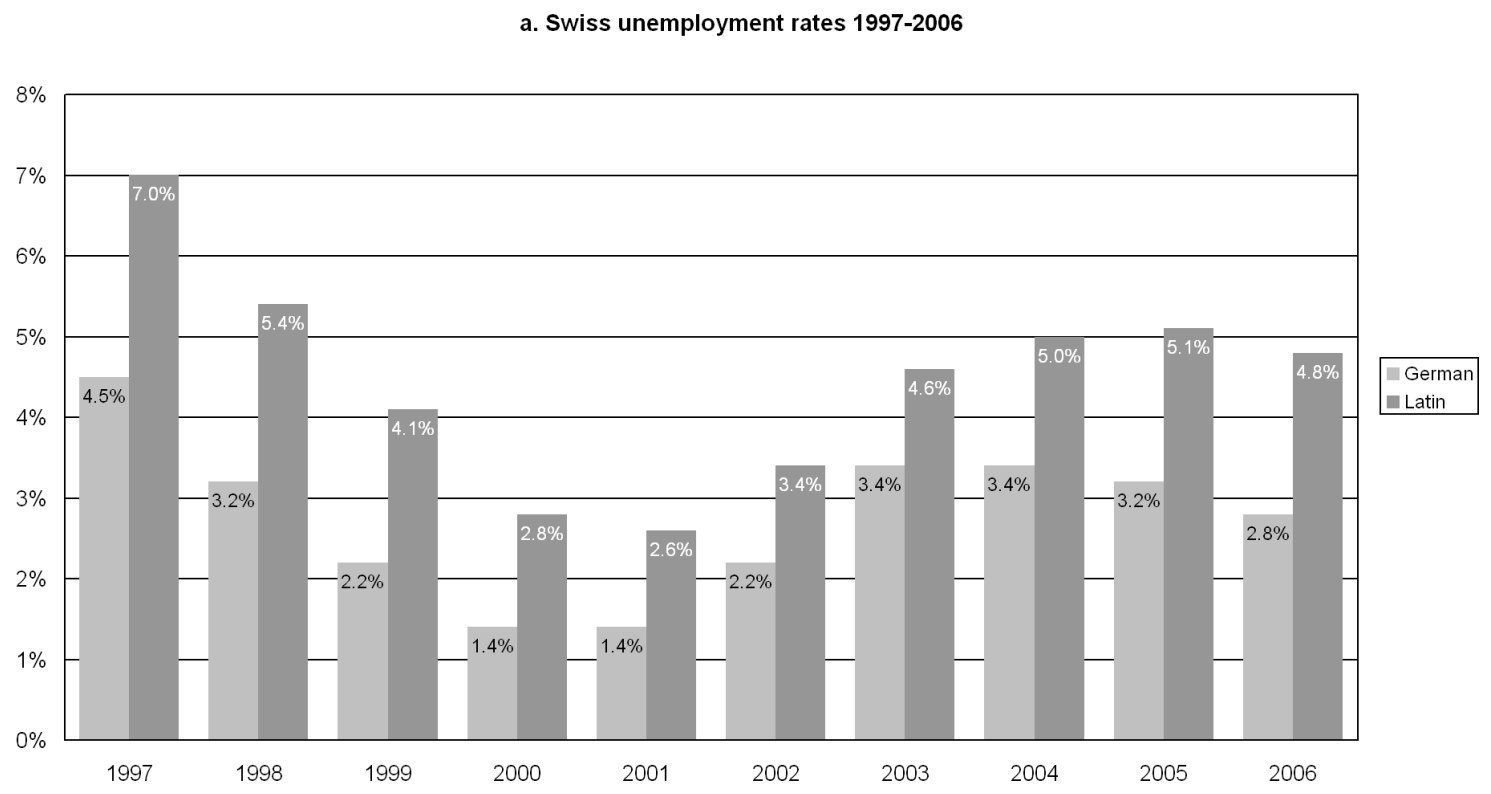

Source: data from Federal Statistical Office (FSO), Neuchâtel.

To what extent can these differences be rationalized by differences in unemployment insurance? Unemployment insurance is organized at the national level. Federal unemployment benefit rules are relatively generous. Maximum benefit duration is 2 years. The marginal replacement rate is $70 \%$ or $80 \%$ depending on the presence of dependent family members and previous income. Job seekers are entitled to these benefits if they have paid unemployment 
insurance taxes for at least six months in the two years prior to registering at the public employment service (PES) and if they are capable of doing a regular job. Entitlement criteria to unemployment benefits also include compliance with job search requirements and participation in active labor market programs. Potential job offers are supplied by the public vacancy information system of the PES, from private temporary help firms or from the job seeker's own pool of potential jobs. Non-compliance with any of these obligations is sanctioned by complete withdrawal of benefits for a period that can last up to 30 work days (see Lalive et al 2005 for details on the Swiss sanction system). This means that differences in benefit duration and level can not explain differences in regional unemployment. Yet regions have an important role in implementing counseling and monitoring practices thus potentially contributing to regional differences in unemployment (Lalive et al 2005, Gerfin and Lechner 2002, Froelich and Lechner 2004). The empirical analysis will pay particular attention to the role of differences in policy implementation in explaining regional unemployment.

\subsection{Language regions and attitudes toward works}

To which extent can regional differences in unemployment be explained by cultural differences between language regions? To shed light on this issue we look at differences in attitudes towards work by language regions. Switzerland has four official languages. ${ }^{6}$ The North East of Switzerland speaks Swiss German, the West speaks French, the South East speaks Italian, and some parts of the East speak Romansh. According to the population census 2000, 72.5 percent of Swiss citizens speak German, 21.0 percent speak French, 4.3 percent speak Italian, 0.6 percent speak Romansh and 1.6 percent speak other languages (Lüdi and Werlen, 2005). ${ }^{7}$ The empirical analysis contrasts the regions speaking languages derived from Latin - French, Italian, Romansh - with the regions speaking German. Figure 1 displays a map of all communities of Switzerland shaded according to their majority language (light shading = majority speaks German; dark shading $=$ majority speaks language derived from Latin). Note that thin lines separate communities, and thick lines separate the 26 Swiss cantons (i.e. states).

Large parts of the language border are neither a geographical barrier nor an institutional border. On the one hand, the most important segment of the language border runs from North to South (the border between French-speaking and German-speaking regions) whereas the main geographical barrier, the Alps, are in East-West direction. This fact, together with a very efficient (public) transportation system implies that transport costs within language regions are similar to transport costs across language regions (conditional on distance). On the other hand, important segments of the language border do not coincide with borders between cantons

\footnotetext{
${ }^{6}$ Switzerland has 7.5 million inhabitants populating an area of 41,300 sq km (15,900 sq mi) with implies a population density of 180 residents per sq $\mathrm{km}$ (480 residents per sq $\mathrm{mi}$ ).

${ }^{7}$ The numbers in the text refer to the Swiss citizens. Roughly 20 percent of residents are immigrants of which 62.3 percent speak either German, French, Italian or Romansh and 37.7 percent have some other first language. Romansh is one of the Rhaeto-Romance languages, believed to have descended from the Vulgar Latin variety spoken by Roman era occupiers of the region, and, as such, is closely related to French, Occitan and North Italian.
} 
Figure 2: Language regions in Switzerland

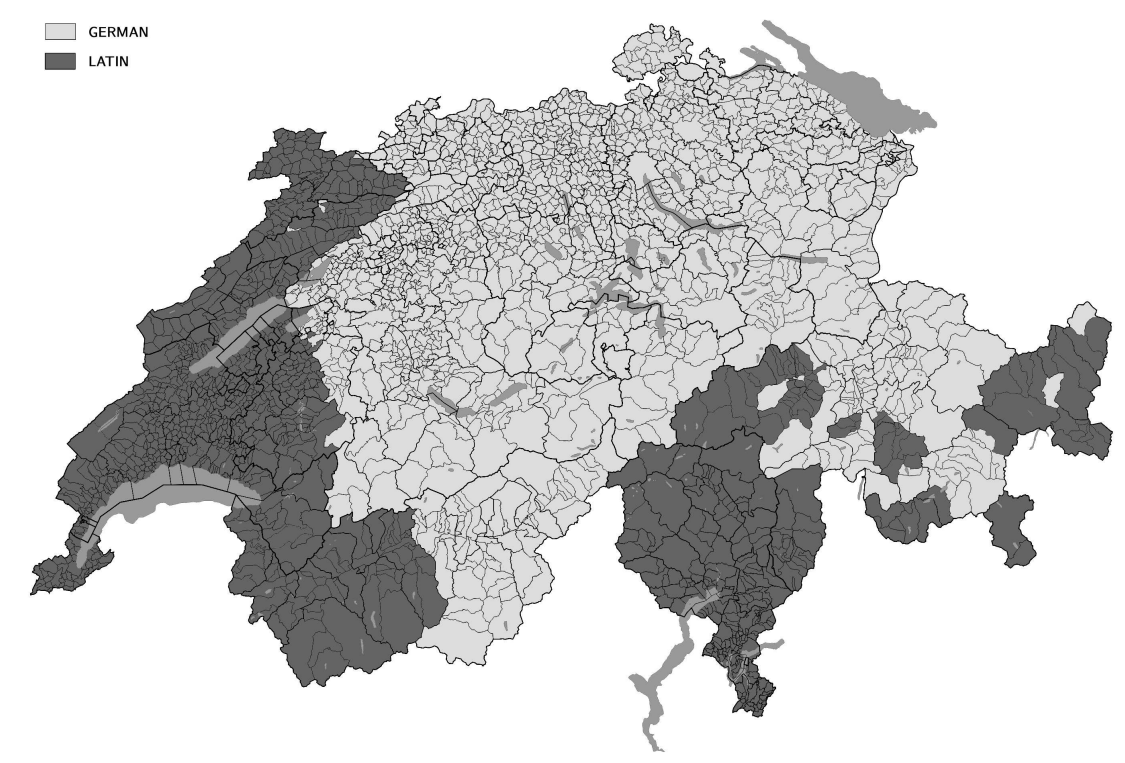

Notes: White-shaded areas are communities in which the majority of the population speaks German, gray-shaded areas are communities with the majority speaking either French, Italian or Romansh. Source: data from Federal Statistical Office (FSO), Neuchâtel.

(dark lines). Specifically, there are three cantons - Berne, Fribourg, and Valais - feature both a German speaking and a French speaking part and are officially bilingual. Thus, people living on different sides of the language border actually face predominantly the same regional set of policies and institutions.

The key argument of this paper is that linguistic groups in Switzerland have adopted different attitudes towards working. Language is central to this idea for at least three reasons. First, language is a key source of identity (Aspachs-Bracons et al. 2008) and language is central to mixing - genetic markers differ more strongly between people living in Latin Swiss area and the German Swiss area than within those regions (Novembre et al. 2008). Second, the Latin Swiss identity is different from the German Swiss identity. Large parts of French-speaking Switzerland have been dominated by the German Swiss oppressors from Berne during 250 years creating a desire for the French Swiss to distinguish themselves from the ruling German elites and their cultural heritage. Third, the French Swiss live in a climate that has always been very forthcoming. In contrast, the German Swiss nourish the founding myth of the mountain peasant working hard to survive in remote areas of the Alps. The Latin Swiss lean towards their large neighbors whereas the German Swiss emphasize neutrality and independence. ${ }^{8}$

\footnotetext{
${ }^{8}$ This pattern is clearly evident in the voting decisions in a referendum on joining the European Economic Area (1992). Whereas the Latin Swiss overwhelmingly supported integration, the German Swiss did not. Switzerland accommodates different cultures via a mix of strong federalism and education policy. Yet, Switzerland pays particular care to the fact that all federal laws are translated in all four languages. Bilingual cantons (Fribourg,
} 
Is there any evidence of cultural differences in attitudes towards work? The Swiss module of the International Social Survey Programme provides information on the importance of work (ISSP 1997 and 2005). ISSP data contains information on the extent to which survey respondents agree with the statement "I would enjoy a paid job even if I did not need the money". Breaking responses down by interview language, Table 1 shows that German speaking respondents indicate much stronger support for the statement than respondents speaking French, Italian or Romansh. Moreover, support for this statement is stronger in the German speaking region both during a recession (1997 unemployment rate $5.1 \%$ ) as well as in a period of economic upswing (2005 unemployment rate $3.8 \%)$.

Table 1: Importance of Work across Language Groups

\begin{tabular}{lcccc}
\hline & Year & Latin & German & Difference \\
\hline Enjoy a paid job even if I did not need the money $^{a}$ & 1997 & 3.26 & 2.60 & $0.65^{* * *}$ \\
Enjoy a paid job even if I did not need the money $^{a}$ & 2005 & 2.58 & 2.26 & $0.32^{* * *}$ \\
\hline
\end{tabular}

Notes: ${ }^{a} 1=$ strongly agree, $2=$ "agree", $3=$ "indifferent", $4=$ "disagree", $5=$ =strongly disagree". This

table reports the average disagreement with the statement "I would enjoy a paid job even if I did not need the money" by interview language.

Source: ISSP 1997 and 2005, own calculations.

These differences in attitudes towards work as measured in the ISSP data translate into actual voting behavior. The Swiss direct democratic system provides us with the possibility to test the hypothesis that in Latin-speaking parts of the country individuals have different tastes for leisure than in the German-speaking parts of the country. Voter initiatives are a crucial part of the political system and have a long tradition in Switzerland. Basically, anyone who collects more than 100,000 signatures can force the parliament to subject her or his change to the constitution to the popular vote. Over the last years, various voter initiatives - related to working time regulations (the "intensive" margin) - were held at the national level.

In 1985, all Swiss nationals aged 18 years or older - the voting age population - were asked to vote on whether to increase paid vacations to a minimum of 4 weeks; in 1988 whether to reduce regular weekly working time to 40 hours; and in 2002 whether to reduce weekly working time to 36 hours. Moreover, there were three referenda related to lifetime work regulations (the "extensive" margin): in 1988 the population had to vote whether to reduce the statutory retirement age from 65 to 62 for men and from 62 to 60 for women; in 2000 whether to make early retirement more attractive to all workers; and in another vote in 2000 whether to leave the statutory retirement age for women at age 62 (rather than increasing it to 65 years). Table 1 displays the voting results of these six votes, separately for German-speaking and for Latinspeaking cantons.

\footnotetext{
Valais, Berne) provide all state laws in both French and German. Politicians speak their native language but they are expected to understand any of the other languages. The second pillar supporting the Swiss multilingual situation is education. Children learn to speak another "Swiss" language as their second language before they can opt for English. (This has changed recently, however. While this has been understood as key to holding the Swiss confederation together, English has started to become the first foreign language in many schools in the German speaking part of Switzerland).
} 
Table 2: Voting results by language region of six votes on working time regulations

\begin{tabular}{lccc}
\hline & $\begin{array}{c}\text { \% Yes in } \\
\text { Latin Region }\end{array}$ & $\begin{array}{c}\% \text { Yes in } \\
\text { German Region }\end{array}$ & $\begin{array}{c}\% \text { Yes } \\
\text { Total }\end{array}$ \\
\hline & Panel A, "intensive margin" & & \\
Longer vacations (1985) & 0.444 & 0.314 & 0.348 \\
Less working hours (1988) & 0.436 & 0.311 & 0.343 \\
Less working time (2002) & 0.354 & 0.226 & 0.259 \\
& Panel B, "extensive margin" & & \\
Reduce retirement age (1988) & 0.463 & 0.310 & 0.350 \\
Downward flexible retirement age (2000) & 0.625 & 0.402 & 0.460 \\
No increase of retirement age for women (2000) & 0.562 & 0.336 & 0.394 \\
\hline
\end{tabular}

Notes: This table shows mean approval for a series of national voter initiatives regarding the duration of work differentiated by the language spoken by the majority of residents in the community. German $=$ cantons with a German speaking majority, Latin = cantons with a French or Italian speaking majority. Voter turnout has been $34.97 \%$ for vote $1,52.86 \%$ for vote $2,58.26 \%$ for vote $3,42.04 \%$ for vote $4,41.71 \%$ for vote $5,41.66 \%$ for vote 6 . There are no differences in turnout accross language regions.

Source: Community level data from Federal Statistical Office (FSO), CH-2010 Neuchâtel.

Table 2 shows that there are strong differences in voting results between the two language regions and that the Latin-speaking cantons are consistently much more in favor of regulations that allow workers to enjoy more leisure. For instance, in the 1985 referendum, 44.4 percent of the population in Latin-speaking cantons voted in favor of longer vacations whereas only 31.4 percent were in favor of such a regulation in the German speaking cantons. The 1988 and 2002 votes on weekly working time reductions show very similar differences. The same picture emerges when we look at differences in voting behavior on issues related to (early) retirement rules. Over all six referenda, the percentage yes-votes is between 1.4 and 1.7 times as large in the Latin-speaking regions as opposed to the German-speaking regions. We consider this as first evidence consistent with a higher prevalence of a "leisure culture" in Latin-speaking regions as opposed to "workaholic" attitudes in German-speaking regions.

Local unemployment may clearly also affect support for work time reductions - through the "lump of work fallacy", for instance. How important is this reverse channel of causation? We can discuss this by contrasting the votes that took place in the late 1980s where the unemployment rate stood below $1 \%$ and with the three votes that took place in 2000 (unemployment rate $2 \%$ ) and 2002 (unemployment rate $2.5 \%$ ), respectively. The language region differential in support for weekly work time reductions amounts to roughly 12 - $13 \%$ regardless of the aggregate unemployment rate. In contrast, support for proposals to reduce the retirement age is much higher in early 2000 than in 1988 suggesting that voting on early retirement is sensitive to unemployment. Nevertheless, the strong differences in voting on work time reductions are also likely to reflect strong differences in cultural attitudes towards working across Swiss language regions. 


\section{Data and Identification}

\subsection{Data}

Data on unemployment duration and level is drawn from two sources. We use unemployment register data from the years 1998-2003 collected by the local public employment service. Once a job seeker files a claim for unemployment benefits, the case worker enters this claim into the so-called AVAM/ASAL system of the ministry of labor. This system registers the date the claim starts as well as a wealth of information on the individual. Job seekers then see the caseworker on a regularly basis and any new information is updated in the system. A job seeker leaves the database either when he or she finds a new job or for "unknown reasons" (does not show up any more; has moved to a different region; or has exhausted unemployment benefits). A nice feature of the AVAM/ASAL database is information on the way a job seeker found a new job: (i) by own initiative or (ii) by placement via the local labor office. This information will be of particular importance in the empirical analysis below. We use 2000 census data to construct a survey based measure of labor force participation and full vs part time employment. In the decennial census, respondents are asked to provide information on their employment status. We can therefore re-construct a snapshot of the Swiss labor force in December 2000 - the (biblical) reference date for the census. Moreover, census data allows discussing whether the unemployment data from administrative sources agree with survey data on labor supply.

Our unemployment inflow analysis is based on Swiss men aged 25 - 60 because female labor supply may be affected by both differences in work culture and family culture. The lower age bound is set to ensure that the unemployed in our sample have (mostly) finished their education. The upper bound is set to avoid any unemployment spells that directly allow for early retirement. We also restrict attention to people in our sample who are registered as full-time unemployed who are entitled to unemployment benefits. This selection does not critically lower the number of unemployment spells in our sample but it does ensure a homogeneous sample. The census analysis is based on Swiss men aged 15-64 years in the census. We also focus on younger and older age groups to discuss labor market entry and exit.

Both data sources contain information on the socio-economic background of job seekers and census respondents as well as information on the place of residence. Whereas the census data contains information on place of work, the unemployment register data neither informs on where job seekers worked before entering unemployment nor where they work after leaving unemployment. We supplement these data sources with important information characterizing the socio-demographic structure of the community of residence, information on labor demand, and on the implementation of labor market policy. Individual controls include socio-economic characteristics as reported in the AVAM/ASAL data base as well as information on previous employment: age, marital status, number of dependent family members, willingness to commute or move, education, qualification, the sector of previous employment (agriculture, manufacturing, construction, services, tourism, other), previous insured earnings, and the assessment of the caseworker w.r.t. the ease of finding a suitable job. Community controls are taken from the 
Swiss population census 2000 and consists of: structure of population/employment by 5 -year age groups, 5 education groups, and three sectors as well as the percentage of men and immigrants living in the respective community, the total number of inhabitants, and if the community belongs to an agglomeration area or not. Labor demand controls are measured at the community level and include the number of vacancies posted from January to June 2000 per employed resident in the working age population, the 1998 number of jobs, the 1998-2001 changes in both the number of jobs and the number of firms, and the median wage of each community. This information is based on the Swiss firm censuses 1998 and 2001. Finally, ALMP controls include monthly time varying entry rates into four types of active labor market programs (basic course, training programs, employment programs, subsidized jobs) and the benefit sanction rates drawn from the AVAM/ASAL database.

To apply the spatial regression discontinuity design, we organize the data in the following way: for each community $c$ we calculate the driving distance in kilometers to get from community $c$ to the closest community on the other side of the language border. ${ }^{9}$ To reflect both distance and language region, we code the distance measure negatively for communities in the Germanspeaking regions and positively for the Latin-speaking regions. For instance, Geneva - the Westernmost city - is located $+150 \mathrm{~km}$ away from the barrier, St. Gallen, the largest city in the East is $-170 \mathrm{~km}$ away from the border. Zurich is $-100 \mathrm{~km}$ away and Lausanne is $+65 \mathrm{~km}$ away from the language barrier. The city of Fribourg (capital of the bilingual canton Fribourg) is located exactly on the language barrier.

\subsection{Identification}

Comparing unemployment rates in Latin-speaking versus German-speaking cantons as in Figure 1 is suggestive for a potential role of culture for unemployment, but we can not interpret this evidence as causal. While attitudes towards work appear to differ between ethnic groups delineated by language in Switzerland, a simple comparison of these groups is unlikely to be informative on the effects of culture on unemployment. Regional differences in industry structure, education, or shocks to labor demand are clear confounders. To assess whether observed differences in unemployment durations and incidence are causally affected by differences in norms and values we propose a spatial regression discontinuity approach. Let $Y_{i c}$ be the duration of unemployment experienced by individual $i$ living in community $c$. Let $P L_{c} \equiv E_{c}\left(L_{i}\right)$ denote the fraction of Latin speakers in the community of residence $c$ of individual $i$. The following model captures both the effect of individual values on unemployment, and the effects of cultural values in the group on the individual (i.e. the community).

\footnotetext{
${ }^{9}$ Driving distance may not reflect driving time - a more direct measure of opportunity costs of distance. Note, however, that the key purpose of the distance measure is to identify border communities. Identification of these communities does not strongly depend on the nature of the distance measure. For instance, using air distance between communities delivers similar results as using driving distance. This suggests that our main results are not driven by the distance measure we use.
} 


$$
Y_{i c}=\alpha+\beta L_{i}+\gamma P L_{c}+\nu_{i c}
$$

The parameter $\beta$ captures the role of individual culture for unemployment. The idea is that individuals who have been raised in different cultural environments may have different attitudes towards work which in turn shape their job search behavior when unemployed. Thus $\beta$ measures the role of work values that are transmitted from parents to their children - the vertical channel of cultural transmission. In contrast, the parameter $\gamma$ captures the role of work culture prevailing in the community of residence of the individual. Why may community culture be important? There are at least three reasons for why a horizontal channel of transmission may be important. First, social interactions between job seekers and other job seekers may lead to spillovers. ${ }^{10}$ These interactions may be endogenous - job seekers are unemployed longer because other's are seeking for work longer - or contextual - job seekers are directly affected by cultural (language) composition of their community. Second, culturally shaped attitudes towards working give rise to work norms which are enforced via social sanctions. Third, the extent to which information on job openings is shared between workers and job seekers may vary across cultural groups.

Clearly, simple least squares identification of the parameters will fail since language skills are important in job finding, and language groups tend to be located in different geographical regions with different markets and institutions. ${ }^{11}$ How can we identify the role of work culture on unemployment?

The key idea of spatial regression discontinuity is that geographic proximity preserves differences in culture but lets differences in employment opportunities and institutions vanish. In other words, observed differences in unemployment at the Röstigraben reflect differences in behavior generated by differences in norms and values rather than by differences in labor markets and/or institutions. Local contrasts at the language border identify the effect of culture on unemployment if this assumption is satisfied. Thus, let $S_{c}$ denote the driving distance of community $c$ to the language border where $S_{c}>0$ identifies a community in the Latin speaking part and $S_{c}<0$ is a community on the German speaking side of the language border (as defined in the previous subsection). Let $E_{+}(Y)$ denote the limit of the expectation of $Y$ on the Latin side of the language border, i.e. $E_{+}(Y) \equiv \lim _{\epsilon \rightarrow 0} E\left(Y \mid S_{c}=\epsilon\right)$, with $E_{-}(Y)$ denoting the corresponding expectation when approaching the language border from the German side. Contrasting unemployment outcomes as defined in equation (1) at the border, we find that the border contrast is composed of three components

\footnotetext{
${ }^{10}$ Note that the reduced form model 1 may be derived from a standard linear-in-means model of social interactions where group unemployment and group language structure affects individual unemployment, i.e. $Y_{i}=\alpha^{\prime}+\beta^{\prime} L_{i}+\gamma^{\prime} E_{c}\left(Y_{i}\right)+\delta^{\prime} P L_{c}+\nu_{i c}^{\prime}$, where $E_{c}\left(Y_{i}\right)$ is the peer group average unemployment outcome. The parameters in model (1) then represent the reduced form parameters obtained by replacing $E_{c}\left(Y_{i}\right)$ in the linear-in-means model and solving for the underlying determinants. In particular $\alpha=\alpha /\left(1-\gamma^{\prime}\right), \beta=\beta^{\prime}$, $\gamma=\left(\delta^{\prime}+\gamma^{\prime} \beta^{\prime}\right) /\left(1-\gamma^{\prime}\right)$, and $\nu_{i c}=\nu_{i c}^{\prime}+\gamma^{\prime} /\left(1-\gamma^{\prime}\right) E_{c}\left(\nu_{i c}^{\prime}\right)$.

${ }^{11}$ Note that specification (1) imposes a homogeneity assumption on the treatment effect. Relaxing this assumption does not lead to fundamentally different conclusions regarding the conditions needed for identification but it does change the interpretation of the identified effects (Hahn et al 2001).
} 


$$
E_{+}\left(Y_{i}\right)-E_{-}\left(Y_{i}\right)=\beta\left[E_{+}\left(L_{i}\right)-E_{-}\left(L_{i}\right)\right]+\gamma\left[E_{+}\left(P L_{c}\right)-E_{-}\left(P L_{c}\right)\right]+\left[E_{+}\left(\nu_{i c}\right)-E_{-}\left(\nu_{i c}\right)\right]
$$

This simple analysis shows two key results. The first result is that we can identify whether culture plays any role or not by investigating whether labor market outcomes are discontinuous at the language border. The key idea in this result is that a language barrier separates culture (giving rise to discontinuities in own culture and other's culture) without separating markets. Thus, the key underlying identifying assumption for (2) to provide valid causal evidence on any role of culture is that the error term $\nu_{i c}$ is mean independent of the language region at the language border. In other words, the identifying assumption is that there are no unobserved differences in regional labor market development at the language border. There are three important concerns with this assumption: unemployment differences could simply reflect (i) regional differences in labor market opportunities; (ii) regional differences in how unemployment insurance is implemented; and/or (iii) sorting across the language border. Section 4 below discusses the validity of these concerns in detail. The key result of that discussion is that labor demand is balanced, labor market policy changes at the language border in ways that are unlikely to be quantitatively important, and there is no sorting across the language border among migrants, arguably the most mobile group.

We propose to measure the contrast (2) in the context of a simple linear regression. Let $L_{c}=1$ if more than $50 \%$ of Swiss residents of community $c$ speak French, Italian, or Romansh, and $L_{c}=0$ if the majority's language is German. Consider the following linear regression

$$
Y_{i}=\pi_{0}+\pi_{1} L_{c}+\pi_{2} S_{c}+\pi_{3} L_{c} S_{c}+X_{i c}^{\prime} \delta+\nu_{i c}
$$

where $X_{i c}$ is a vector of variables that capture differences between individuals, communities, markets, and local labor market policies. Furthermore, the vector $X_{i c}$ contains a full set of canton and time dummies to account for unobserved differences between states and over time. The terms in $S_{c}$ and $L_{c} S_{c}$ capture a two sided linear trend between unemployment duration and distance to language border. The parameter estimate for $\pi_{1}$ is a consistent estimate of (2), provided that our specification appropriately captures differences in unemployment outcomes across regions.

The second result of the analysis (2) is that contrasting unemployment outcomes does not allow differentiating between vertical and horizontal transmission of culture. Because both individual language and the community's language change discontinuously at the language border, the parameter $\pi_{1}$ measures the overall effect of culture on unemployment. How can we disentangle the effects of one's own cultural values from the effect of one's neighbors culture? Understanding the role of vertical cultural transmission requires shutting down the channel of horizontal cultural transmission, i.e. contrasting individuals with different native languages $L_{i}$ in the same language region $L_{c}$ - as is common in the epidemiological approach to identifying culture (Fernández 2007). In principle, this is possible because there is within region variation 
in native language. About $6 \%$ of all job seekers who live in the Latin speaking region have a mother who spoke German, and about $3 \%$ of all job seekers in the German speaking region spoke either French, Italian or Romansh with their mother. The key problem with this identification strategy is that it requires comparing people who do not live in the region speaking their native language (movers) with job seekers who live in a region that speaks their language (stayers). There are at least three reasons why these two groups might differ. First, not speaking the region's language may harm labor market success. Second, movers tend to be a positively selected group of the overall population. Third, movers may adapt to the prevailing cultural values.

How relevant are these concerns? First, note that we can measure the role of vertical transmission of values both in the Latin speaking and the German speaking region. If there are any differences in unobserved labor market chances $\nu_{i c}$ between movers and stayers, we will detect this in terms of an asymmetric estimate of the role of vertical transmission $\beta{ }^{12}$ Second, note that adaptation is a problem for all studies adopting the epidemiological approach. Adaptation to local cultural values tends to decrease the importance of vertical cultural transmission thus changing the parameter being identified. While the full extent of vertical transmission can not be detected with mover stayer contrasts, they capture the extent to which cultural values persist in situations where the individual is exposed to other cultures. Moreover, we will go one step beyond existing studies in measuring the vertical transmission of culture in the bilingual city of Fribourg. Fribourg provides us with a unique situation where two cultural groups reside in the same geographic location in a non-segregated fashion. This suggests that residents of Fribourg are similarly affected by horizontal transmission of culture allowing us to study the role of vertical transmission without adaptation.

Our empirical identification strategy to separate vertical and horizontal transmission proceeds as follows. We control for language skills by adding the information on one's native language not being equal to the language spoken by the majority in the community, i.e. $N_{i c} \equiv$ $L_{i} \neq L_{c}$. This variable captures the extent to which individuals whose native language is not identical to the local language experience differential unemployment durations than individuals who are able to speak the local language perfectly. Specifically, we modify equation (3) as follows

$$
Y_{i}=\alpha+\beta L_{i}+\pi_{1} L_{c}+\delta N_{i c}+\pi_{2} S_{c}+\pi_{3} L_{c} S_{c}+X_{i c}^{\prime} \delta+\nu_{i c}
$$

\footnotetext{
${ }^{12}$ To see this, note that comparing Latin to German speaking job seekers in the Latin region provides information on $E\left(Y_{i} \mid L_{i}=1, L_{c}=1\right)-E\left(Y_{i} \mid L_{i}=0, L_{c}=1\right)=\beta+E\left(\nu_{i c} \mid L_{i}=1, L_{c}=1\right)-E\left(\nu_{i c} \mid L_{i}=0, L_{c}=1\right)$ whereas comparing Latin to German speaking job seekers in the German speaking region of Switzerland measures $E\left(Y_{i} \mid L_{i}=1, L_{c}=0\right)-E\left(Y_{i} \mid L_{i}=0, L_{c}=0\right)=\beta+E\left(\nu_{i c} \mid L_{i}=1, L_{c}=0\right)-E\left(\nu_{i c} \mid L_{i}=0, L_{c}=0\right)$. These contrasts only measure the same parameter if a) there is no stayer mover difference in labor market skills, or b) if there is stayer advantage in the Latin region but a stayer disadvantage in the German region - or vice versa. Asymmetric stayer advantage in labor market success is not plausible because language skills are likely to favor stayers in both language regions, and movers are arguably positively selected from the respective populations. Even though tougher labor market competition in the German region introduces some asymmetry in the labor market skills of movers to the German and to the Latin region, the two contrasts would still provide different estimates.
} 


\section{The effect of culture on unemployment}

In this section we assess whether there exist significant discontinuities in unemployment durations at the Röstigraben. We start by documenting the significance of the Röstigraben as a language barrier and show the extent to which unemployment durations change at the language border. Under the assumption that geographic proximity to this language barrier preserves differences in culture but does not imply a segmentation of labor markets and the institutional environment, observed differences in unemployment outcomes can be interpreted as the causal effect of culture on unemployment. To check the plausibility of this identifying assumption we proceed as follows. We address in detail the key concern that the Röstigraben is a barrier that segments labor markets. We then go one step further and provide detailed regression analyzes that check to which extent observed language-border differences can be attributed to standard explanations commonly associated with differences in unemployment outcomes.

\subsection{Discontinuities in language and unemployment}

We start by exploring how sharply the dominant native language changes at the Röstigraben. Figure 3 shows the percentage unemployed with Latin (i.e. French or Italian) native language by distance to the language border. The figure clearly demonstrates that the Röstigraben is a sharp language barrier. In the German-speaking parts of the country (negative distance measure) the percentage of Latin native speakers is very small, considerably less than 10 percent. More importantly, the percentage native Latin speakers does not show a clear trend when we approach the Röstigraben. At the language border, there is a sudden jump from about 20 percent Latin-speakers on the side of the German language area to more than 80 percent on the Latindominated side. Notice that this change occurs within a distance of $10 \mathrm{~km}$, the grid adopted in the Figure. Hence we conclude that the language border delineates quite sharply the two language regions.

In Section 2 above we have already documented the striking differences in unemployment outcomes between German-speaking and the Latin-speaking cantons. If culture is a first-order determinant of these differences we should see a discontinuous change in unemployment not only between entire language areas, but also at the Röstigraben. In Figure 4, we draw the average duration of unemployment experienced by residents located at different distances from this border. This graph clearly shows a strong discontinuity of average unemployment durations at the language border. On the German-speaking side the average duration of unemployment is about 29 weeks. On the Latin-speaking side the corresponding value is about 35 weeks. In either direction, we do not observe a strong trend (with respect to distance from the border) in unemployment outcomes.

Table 3 presents unemployment durations for the two language regions together with two estimates for the differential at the language border. Row 1 suggests that the difference in unemployment duration between language regions is very high (10 weeks), but probably driven to some extent by different economic structures (column 4). Using model (3) without controls, we 
Figure 3: Percentage Latin-speakers (French, Italian or Romansh), by distance to language border

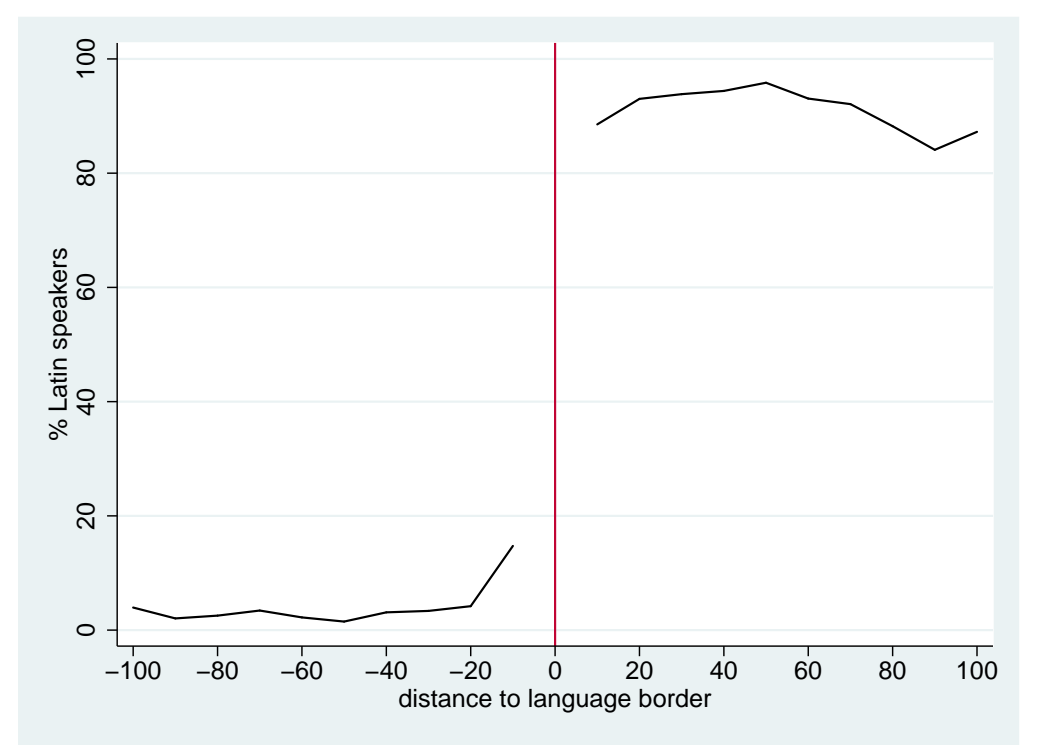

Notes: negative=German-speaking part; positive $=$ French- $/$ Italianspeaking part.

Source: Swiss Census 2000, Federal Statistical Office (FSO), Neuchâtel.

Figure 4: Average durations of unemployment, by distance to language border

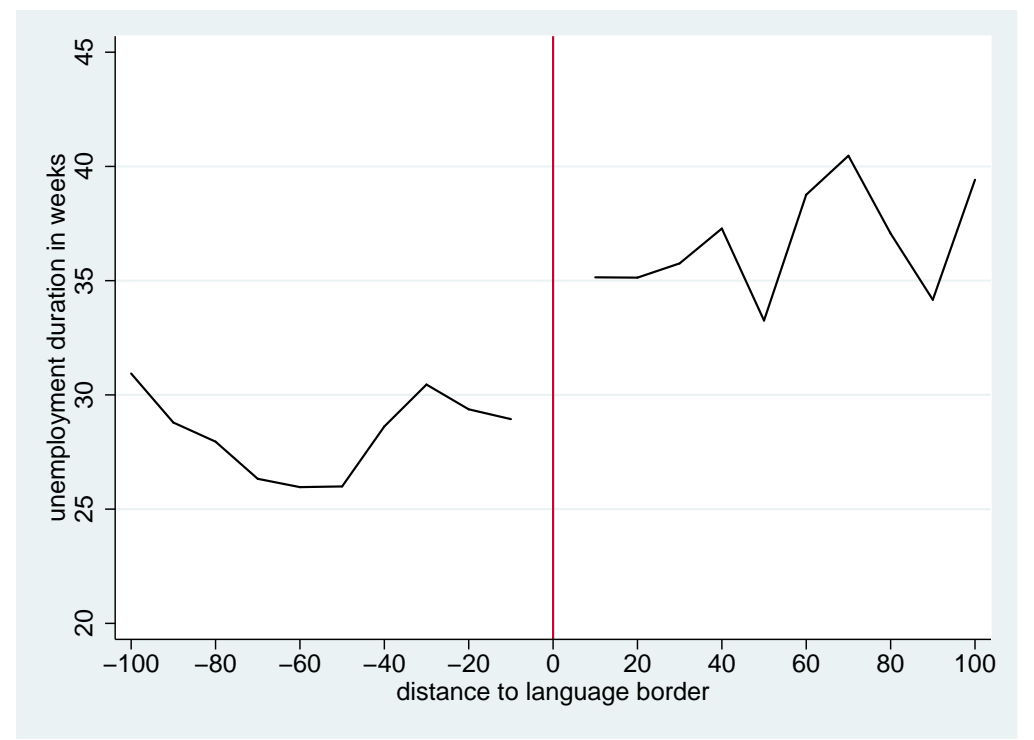

Notes: negative $=$ German-speaking part; positive $=$ French- $/$ Italianspeaking part.

Source: Unemployment Register 1998-2003, Federal Statistical Office (FSO), Neuchâtel.

estimate the corresponding difference directly at the language border (column 5). This estimate may be biased if the relationship between unemployment duration and distance to langauge 
border is misspecified. Addressing this important issue, we therefore report estimates of model (3) that only use information from three bilingual German/French cantons (Fribourg / Valais / Berne). Findings in column (6) show that the language border difference in unemployment duration remains at a level of 6 weeks. Row 2 in Table 3 also presents estimates for log unemployment duration which should be less affected by outliers. Results indicate that log unemployment duration increases by .19 points using information on all Switzerland or by .21 points using bilingual cantons. These estimates translate into changes of unemployment duration that are of similar order of magnitude as the duration estimates.

Table 3: Summary statistics: Dependent variables

\begin{tabular}{lcccccc}
\hline & $(1)$ & $(2)$ & $(3)$ & $(4)$ & $(5)$ & $(6)$ \\
& All & Latin & German & Difference & $\begin{array}{c}\text { Difference at border } \\
\text { All }\end{array}$ & Bilingual cantons \\
\hline Unemployment duration (weeks) & 32.12 & 39.12 & 29.07 & $10.05^{* * *}$ & $6.34^{* * *}$ & $6.18^{* * *}$ \\
Log unemployment duration & 4.89 & 5.16 & 4.77 & $.38^{* * *}$ & $.19^{* * *}$ & $.21^{* * *}$ \\
No. of observations & 173072 & 52317 & 120755 & & 173072 & 34528 \\
\hline
\end{tabular}

Notes: Latin = majority in community speaks French, Italian or Romansh. Difference at the border is estimated using linear specifications. Source: Data from Unemployment Register 1998-2003, Swiss Census 2000, Federal Statistical Office (FSO), CH-2010 Neuchatel.

Notice that a 6 weeks difference in unemployment durations is quantitatively significant. To see recall the effects of unemployment insurance parameters as estimated e.g. by Katz and Meyer (1990). Their analysis indicates that an increase in maximum benefit duration by 10 weeks increases actual durations of unemployment by one week. Extrapolating this effect linearly, a six-week difference in unemployment duration arises from increasing the maximum benefit duration of unemployment benefits by more than a whole year! We therefore conclude that the difference in unemployment durations at the Röstigraben is strikingly large. To what extent is this difference driven by differences in labor demand and labor market integration?

\subsection{Does the Röstigraben segment labor markets?}

An obvious concern against the cultural interpretation of language-border effects in unemployment outcomes is that these differences may reflect labor market conditions. We address this central issue in two different ways.

First, we explore the extent to which labor markets are integrated by looking at the extent of daily commuting across the language border. The idea is that, with a substantial pool of commuters, differences in labor market conditions should be arbitraged away by worker mobility. To the extent that this is the case, our identifying assumption becomes more plausible. Figure 5 a draws the percentage of daily commuters who cross the Röstigraben when going to work, by distance to the language border of the residence community. (The figure is based on data 
from the Swiss population census 2000). The figure shows that about 8 percent of employed residents of German border communities commute to a workplace located in the Latin area. In contrast, about 14 percent of employed residents of Latin border communities commute to the German speaking area. This shows that the language border is permeable. The second finding is that whereas the share of within canton migration is symmetric, excess cross border work mobility arises due to residents of Latin border communities taking jobs in the German area outside of their canton of residence. The asymmetry in across region mobility indicates that there are features of the German side of the language border which make it more attractive to Latin residents than vice-versa. On the other hand, the finding of balanced within canton cross language border mobility indicates that the asymmetry does not arise within but across cantons. We consider such a high extent of mobility across the language border as strong evidence in favor of an integrated labor market and against the concern that the Röstigraben is a rift that segments local labor markets.

Figure 5: Are Labor Markets Integrated?

a. Cross-Border Mobility

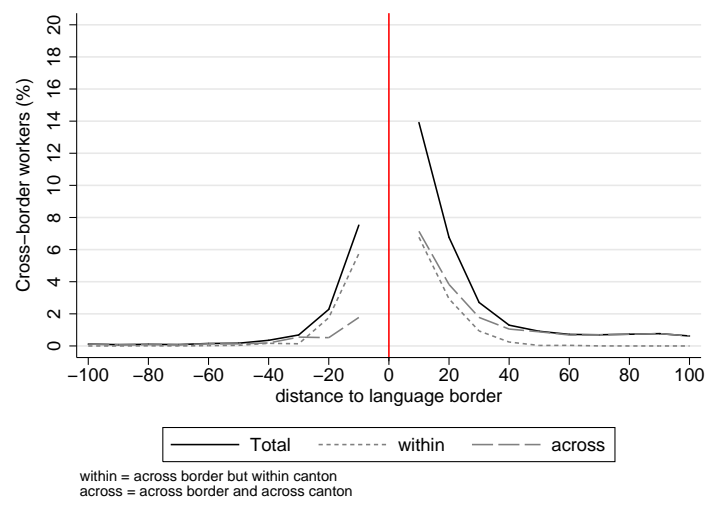

b. Commuting

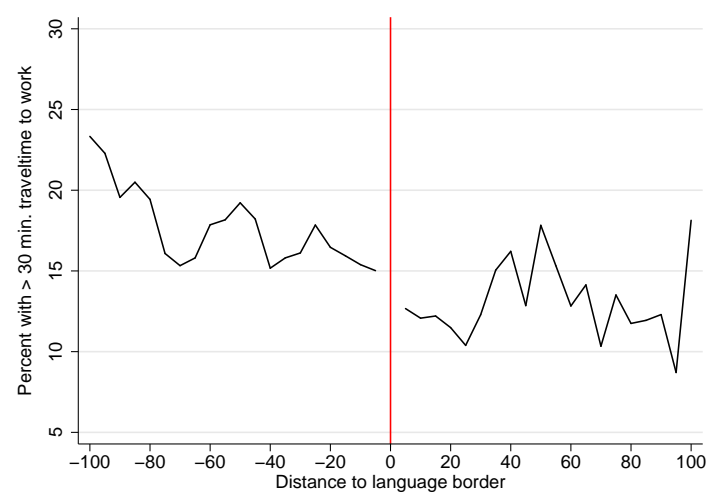

Notes: negative=German-speaking part; positive=French-/Italian-speaking part. Figure a shows the share of workers crossing the language border to reach their place of work, where a solid line = all workers, a dashed line $=$ workers crossing the language border to a place of work in their canton of residence, a dotted line $=$ workers crossing the language border to a workplace that is outside the canton of residence. Figure $\mathrm{b}$ shows the share of workers commuting for more than 30 minutes to reach their place of work. Source: Swiss Census 2000, Federal Statistical Office (FSO), Neuchâtel.

Commuting times also allow studying the extent of labor market integration. If the language barrier separates markets, workers living close to the border will be forced to search further away from their place of residence. This suggests that commuting times will tend to be higher in communities that are close to the language border than in communities that are further away from the border. The empirical evidence is exactly in contrast to this idea (Figure 5b). Both in the Latin speaking area and in the German speaking area, commuting times tend to be lower closer to the border than further away. What is more, there is no discontinuity in the fraction commuting more than 30 minutes to their workplace at the langauge border. This evidence suggests both that the language border does not constrain job search radius in a one sided fashion and that commuting patterns are similar at the language border.

The second question is whether labor market success would be identical in the absence of 
cultural differences. A direct measure of labor demand is the number of open vacancies in each community per employed person (Figure 6a). The Swiss firm census provides information on all vacancies that were created by firms between January and June 2000. Interestingly, the figure suggests that the vacancy to employment rate is slightly higher on the Latin speaking side of the language border. This suggests that labor market chances are slightly better on the Latin side of the language border than on the German speaking side of the language border.

Figure 6: Is Labor Demand Balanced?

a. Vacancies

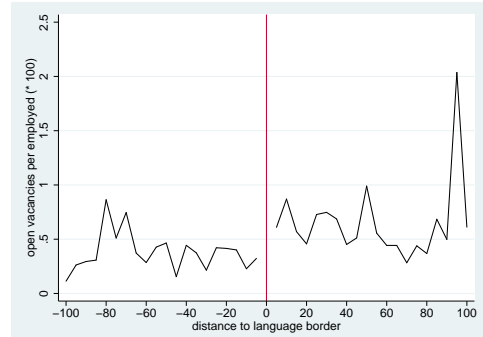

b. Migrants

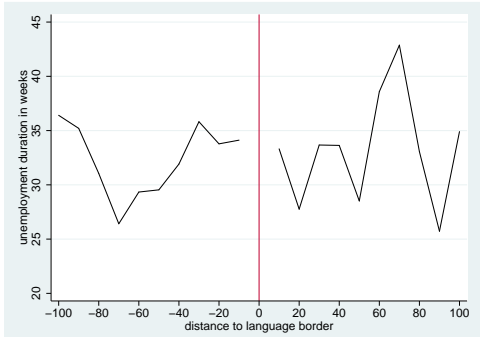

c. Migrant Share

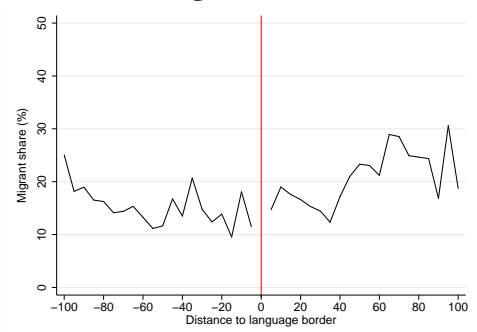

Notes: negative=German-speaking part; positive=French-/Italian-speaking part. Figure a shows the vacancies posted by firms between January and June 2000 in each community per number of employed individuals in the working age population (16-64 years) living in that community. Figure b shows average log unemployment duration for job seekers for non Swiss citizens whose native language is neither of the languages spoken in Switzerland. Figure c shows shows the share non-Swiss residents.

Source: Unemployment Register 1998-2003, Swiss Census 2000, Federal Statistical Office (FSO), Neuchâtel.

We also provide descriptive evidence on immigrants who are neither German native speakers nor Latin native speakers (whereof 29\% immigrants from former Yugoslavia, 12\% from Portugal, and $11 \%$ Turkish immigrants). This group has a cultural background dissimilar from both the Latin-Swiss and the German-Swiss culture. Thus comparing unemployment experiences of these immigrants by Swiss language regions should not be driven by culture but should be attributed to differences in the labor markets. Figure $6 \mathrm{~b}$ reports unemployment duration of this group of migrants. Clearly, the figure shows that there are no salient differences in unemployment durations for immigrants with a non-German and non-Latin cultural background, i.e. a group of job seekers who do not share norms and views expressed by Swiss residents. ${ }^{13}$ This is a second piece of evidence suggesting that labor market chances are similar on both sides of the Röstigraben.

The ultimate question refers to job competition among Swiss natives and non-Swiss immigrants. The Latin speaking area of Switzerland is characterized by a substantially higher share of non-Swiss population than the German speaking area. Thus, competition for jobs is stronger in the Latin-speaking area than in the German speaking are. Yet does this also hold for communities located close to the language border? Figure $6 \mathrm{c}$ suggests that the migrant share is balanced right at the language border. Both German speaking border communities and Latin speaking communities are characterized by a migrant share on the order of $18 \%$. This evidence

\footnotetext{
${ }^{13}$ Table 7 confirms that there is no significant difference in log unemployment duration in a regression setting that controls for canton dummies, individual characteristics, community characteristics, and labor market policy controls.
} 
is consistent with symmetric job competition across the language border within Switzerland. ${ }^{14}$ Moreover, Figure 6 also suggests that regional sorting by immigrants is not relevant. First, the migrant share is balanced at the language border, and second there are no differences in unemployment duration at the langauge border. ${ }^{15}$

Taken together, ex ante evidence suggests that the language border does not separate labor markets, that labor market chances are similar across the border, and that there is not differential job competition between Swiss and non-Swiss migrants.

\subsection{Assessing the Röstigraben gap in unemployment}

In this subsection we go one step further and provide results from regression analyses that account in detail for regional differences in the economic and institutional environment. The above descriptive graphical analysis did not control for socio-economic characteristics of individual job-seekers, so the specific reason for the observed border-discontinuity in unemployment remains unclear. Therefore we investigate whether the barrier effect survives once we introduce, sequentially, four groups of variables: (i) the composition of the unemployment pool with respect to human capital and other socio-economic characteristics; (ii) labor demand conditions (availability of jobs, vacancies, changes in jobs and firms); (iii) community characteristics (age structure, average education levels, and urbanization/agglomeration); and (iv) implementation of labor market policies (treatment intensities with active labor market policies and sanction rates).

Table 4 shows the estimated effect at the language border based on equation (3). All regressions in Table 4 control for inflow year and quarter, for canton (=state) dummies, and a set of dummies for large cities. ${ }^{16}$ Introducing canton dummies is of particular importance in the present context because cantonal borders are also institutional borders and because cantonal dummies account for persistent regional differences in labor market conditions.

Column 1 includes a large set of individual characteristics in the regression (skills, sector of last job, employment prospects assessed by the caseworker, previous earnings, family background, willingness to move to another region). Controlling for the above set of variables, we find a language border differential in log unemployment durations of .237 log points. Evaluated at the sample mean, roughly 32 weeks, this is equivalent to a 7.5 weeks difference in average durations of unemployment at the language border. This means that, after controlling for a detailed set of characteristics, the estimated language barrier effect does even become somewhat larger than the raw differential observed at the language border in figure 4 above. The language

\footnotetext{
${ }^{14}$ One might argue that there is asymmetric job competition at the Swiss/French border. Note, however, that we also find a strong difference in mean unemployment duration for bilingual cantons. Two of these three cantons (Fribourg and Berne) do not have common borders with the national border between Switzerland and France. Moreover, the national border lies in Alpine region for the third canton (Valais). Job competition is therefore not an issue.

${ }^{15}$ Note that the share of non-Swiss who do not speak a language spoken in Switzerland is also balanced across the language border reaching a level of about $6 \%$.

${ }^{16}$ We control for large cities because they may be driving the distance to border effects in the regressions.
} 
Table 4: The language barrier effect in unemployment durations

\begin{tabular}{lcccc}
\hline & $(1)$ & $(2)$ & $(3)$ & $(4)$ \\
& lndur & lndur & lndur & lndur \\
\hline Latin & $0.237^{* * *}$ & $0.241^{* * *}$ & $0.244^{* * *}$ & $0.215^{* * *}$ \\
& $(0.039)$ & $(0.032)$ & $(0.032)$ & $(0.031)$ \\
Distance & -0.0317 & $-0.0987^{* * *}$ & $-0.0979^{* * *}$ & $-0.0948^{* * *}$ \\
& $(0.031)$ & $(0.029)$ & $(0.029)$ & $(0.028)$ \\
Distance-Latin & $-0.0596^{* * *}$ & 0.0143 & 0.00926 & 0.00205 \\
& $(0.013)$ & $(0.013)$ & $(0.014)$ & $(0.014)$ \\
Constant & $2.583^{* * *}$ & $2.493^{* * *}$ & $2.345^{* * *}$ & $2.363^{* * *}$ \\
& $(0.077)$ & $(0.208)$ & $(0.222)$ & $(0.224)$ \\
& & & & \\
Individual controls & Yes & Yes & Yes & Yes \\
Community characteristics & No & Yes & Yes & Yes \\
Labor demand & No & No & Yes & Yes \\
ALMP controls & No & No & No & Yes \\
\hline Observations & 173072 & 173072 & 173072 & 173072 \\
$R^{2}$ & 0.123 & 0.126 & 0.126 & 0.126 \\
\hline
\end{tabular}

Notes: Robust standard errors in parentheses. ${ }^{* * *} \mathrm{p}<0.01,{ }^{* *} \mathrm{p}<0.05,{ }^{*} \mathrm{p}<0.1$. Latin $=$ majority in community speaks French, Italian or Romansh. Distance $=$ distance to language border (in 100 kilometers road distance). All designs include control dummies for year, quarter, canton (state) and for large cities. Other controls are individual characteristics (age, marital status, no. of dependents, qualification, employability, previous earnings, previous industry and mobility). Community characteristics are education, sector, age and $\%$ of people that speak another than the official languages. Labor demand controls are number of firms, \% change in no. of firms and available jobs from 1998 to 2001 and vacancies per working age population. Labor market policy controls are a community average of sanction rates, ALMP assignment rates for training course, employment programs, and subsidized jobs. Source: Data from Unemployment Register 1998-2003, Swiss Census 2000, Federal Statistical Office (FSO), CH-2010 Neuchatel.

barrier effect is estimated using linear distance-to-language border trends, separately for the Latin-speaking and the German-speaking side of the language border.

To check the robustness of this effect, the remaining 3 columns of Table 4 introduce additional controls. Column 2 controls for community characteristics (community education levels, demographic structure, community size, and a dummy that indicates whether the community belongs to suburbs of an urban center (agglomeration)). Although most of these variables (in particular, age structure, education levels, and community size) have a statistically significant impact on unemployment durations, introducing these additional controls does not change the 
magnitude of the language barrier effect. In contrast, the point estimate even increases slightly to .241. Column 3 checks for labor demand conditions within cantons (i.e. in addition to persistent differences in labor market conditions across canton that are captured by the cantonal dummies). We introduce detailed community indicators to capture local differences in labor demand. The number of available jobs in the community (in the base year 2001); the increase in the number of jobs and the increase in the number of firms at the community level between the years 1998-2001; and the number of vacancies opened in a community between January and June 2000 per employed resident in the working age 16-64 years. Introducing these detailed labor market indicators does neither have a strong impact on the overall performance of the estimated equations; nor does it have an impact on the estimated language barrier effect on unemployment durations. It appears that differences in labor market conditions are well captured by the cantonal dummies. Column 4 includes indicators for differences in regional ALMP treatment intensities (sanction rates, ALMP assignment rates for training courses, employment programs, and subsidized jobs). Consistent with other studies, these variables contribute to explaining unemployment durations. However, controlling for regional differences in ALMPs does not contribute very much to an explanation of the observed difference in unemployment durations at the language barrier. The coefficient of the Latin-dummy decreases only slightly to .215 .

Why is the unemployment duration differential at the language border so stable? Intuitively, this must be due to the fact that the characteristics we include in columns 1-4 are either balanced on both sides of the language border, or that imbalances are quantitatively unimportant. Detailed summary statistics in the appendix show that contrasting individuals just across the language border reduces the imbalances across language regions considerably. Nevertheless, a number of background characteristics remain imbalanced at the language border in ways that are favoring job seekers on the Latin speaking side of the language border. ${ }^{17}$ Do the differences in observed characteristics contribute to enlarging the difference in unemployment duration? To shed further light on this issue we regress individual, community, labor demand, and ALMP characteristics on log unemployment duration of individuals living on the German speaking side of the language border. We then combine the German parameter estimates with the background characteristics of the Latin speaking job seekers to predict unemployment duration of residents of the Latin speaking side of the border - and vice versa for the German speaking side of the language border. This allows assessing the overall contribution of imbalances in background characteristics to the language border unemployment differential.

Figure 7 shows average actual log unemployment duration (solid lines) as well as average predicted log unemployment duration (dashed lines) for both language regions using the procedure outlined above. Results indicate that there is no noteworthy discontinuity at the language border, neither in a regression based on German-Swiss observations to predict Latin-Swiss unemployment duration nor vice versa. Moreover, both exercises suggest that the observed gap

\footnotetext{
${ }^{17}$ For instance, job seekers on the Latin side are slightly better qualified, easier to place, and more mobile.
} 
in log unemployment is smaller than the one predicted using background characteristics. This explains why results that do control for background characteristics identify a slightly larger language border differential than those that do not account for background characteristics.

Figure 7: Predicted and actual log unemployment duration, by distance to language border

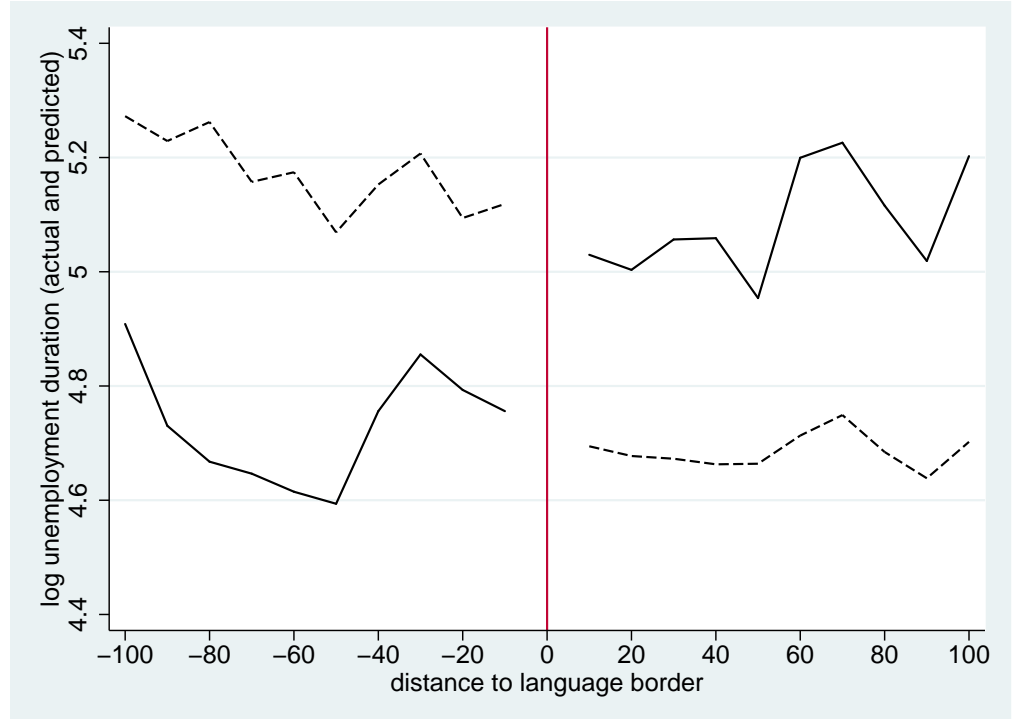

Notes: negative=German-speaking part; positive=French-/Italianspeaking part. Solid lines show actual log unemployment duration. Dashed lines show predicted unemployment duration using data from the German speaking part of Switzerland to predict duration in the Latin speaking part and vice versa. Linear prediction. Source: Swiss Census 2000, Federal Statistical Office (FSO), Neuchâtel.

We next look at the robustness of the estimated effect. Table 5 looks at the unemployment differential at different segments of the language border. Column 1 repeats the estimate of column 4 in Table 4 for ease of comparison. In columns 2 and 3 we restrict the sample to observations along the German-French language border and the German-Italian language border, respectively. That is, in column 2 we use only observation that (i) live in a French-speaking community or that (ii) live in a German-speaking community that has a French-speaking community as nearest neighbor on the other side of the language border. In column 3 we use therefore only unemployed from (i) Italian-speaking communities, or (ii) German-speaking communities that have an Italian-speaking community as nearest language border neighbor.

It is interesting to see that the estimated coefficient for the French-German comparison is almost exactly the same as the one for the whole sample. This is support for the robustness of our specification as the French-German language border accounts for the vast majority of the overall language border. (In fact, the term "Röstigraben" orginally refers to French-German language border only). Column 3 shows that also for the Italian-German language border the point estimate is very close to the baseline estimate of column 1 , but is not statistically significant. Notice, however, that the high standard error is due to the low number of observations on which 
Table 5: Sensitivity analysis: What parts of the border are responsible?

\begin{tabular}{lcccccc}
\hline & $(1)$ & $(2)$ & $(3)$ & $(4)$ & $(5)$ & $(6)$ \\
& Baseline & $\begin{array}{c}\text { French } \\
\text { border }\end{array}$ & $\begin{array}{c}\text { Italian } \\
\text { border }\end{array}$ & $\begin{array}{c}\text { Local } \\
\text { linear Reg. }\end{array}$ & $\begin{array}{c}\text { Bilingual } \\
\text { cantons }\end{array}$ & $\begin{array}{c}\text { Bilingual } \\
\text { PES (FE) }\end{array}$ \\
\hline Latin & $0.215^{* * *}$ & $0.218^{* * *}$ & 0.191 & $0.206^{* * *}$ & $0.207^{* * *}$ & $0.176^{*}$ \\
& $(0.031)$ & $(0.033)$ & $(0.165)$ & $(0.055)$ & $(0.044)$ & $(0.091)$ \\
Distance (100km) & $-0.0948^{* * *}$ & $-0.0830^{* * *}$ & $0.0777^{*}$ & $-0.0918^{* *}$ & -0.0884 & \\
& $(0.028)$ & $(0.031)$ & $(0.045)$ & $(0.047)$ & $(0.078)$ & \\
Distance-Latin & 0.00205 & -0.00432 & $0.221^{*}$ & -0.0036 & -0.0353 & \\
& $(0.014)$ & $(0.016)$ & $(0.127)$ & $(0.019)$ & $(0.140)$ & \\
Constant & $2.363^{* * *}$ & $2.474^{* * *}$ & $3.125^{* * *}$ & 3.445 & $1.598^{* * *}$ & -0.378 \\
& $(0.224)$ & $(0.249)$ & $(0.947)$ & $(1080.02)$ & $(0.456)$ & $(1.708)$ \\
All controls & Yes & Yes & Yes & Yes & Yes & Yes \\
\hline Observations & 173072 & 121367 & 28886 & 93700 & 34528 & 3012 \\
$R^{2}$ & 0.126 & 0.133 & 0.110 & 0.120 & 0.100 & 0.097 \\
\hline
\end{tabular}

Notes: Robust standard errors in parentheses. ${ }^{* * *} \mathrm{p}<0.01,{ }^{* *} \mathrm{p}<0.05,{ }^{*} \mathrm{p}<0.1$. Latin $=$ majority in community speaks French, Italian or Romansh. Distance = distance to language border (in 100 kilometers road distance). Local linear Reg.: Observations are weighted with respect to distance to language border (normal kernel weights with bandwidth $h=5 \mathrm{~km}$ ). Bilingual cantons = canton of Berne, Valais, Fribourg (German / French cantons). Bilingual PES = public employment service offices with both Latin and German speaking job seekers. All controls as in table 4.

Source: Data from Unemployment Register 1998-2003, Swiss Census 2000, Federal Statistical Office (FSO), CH-2010 Neuchatel.

this estimate is based. Since we control for canton fixed effects, identification is based on a few communities with a majority of the Italian-speaking residents in the canton Graubünden. ${ }^{18}$

A method to measure the barrier effect very locally at the language border is to use local linear regression. The result of this specification is reported in column 4 of table 5 . Weighting observations inversely to their border-distance yields a Latin-border effect that is only slightly lower than the one of our baseline specification. Column 5 shows the Latin-effect when taking only observations that live in one of the three bilingual cantons: Berne, Fribourg, and Valais. That is, we are measuring the effect even closer to the language border. The Latin-border effect is almost exactly equal to the one we estimated using local linear regression. The final robustness check, conducted in column 6 of Table 4 analyzes whether our results remain stable when we focus on bilingual public employment offices and include public employment office fixed effects. ${ }^{19}$

\footnotetext{
${ }^{18}$ The only cantons where there are Italian-speaking communities are the canton Ticino and the canton Graubünden, located in the South and the South-East, respectively. The canton Ticino consists entirely of Italian speaking communities. In Graubünden, some communities are Italian, but the vast majority speaks Swiss German.

${ }^{19}$ We do not control for distance to language border because all of these offices are located on the language
} 
This is potentially relevant as regional labor offices have some discretion about implementation of active labor market policies. Including labor office fixed effects still allows us to identify the Latin-effect as there are some bilingual districts. It turns out that the point estimate shows still the same order of magnitude than our baseline estimates of Table 4.

\section{Cultural differences in work attitudes?}

Above we have documented a very large difference in unemployment durations across language regions. We have argued that standard explanations for regional unemployment differences are unlikely to account for the Latin-border effect. To the contrary, accounting for observable individual, labor-market and community characteristics, the border-effect does not disappear but does even become slightly larger. In this section we go one step further and ask whether the estimated Latin-effect can plausibly be interpreted as an effect of cultural differences in attitudes towards work in general and job search behavior in particular. To make the case for the culture explanation we proceed in three steps. First, we look at the particular channel by which unemployed individuals find new jobs. Exploiting information available in the AVAM data base we ask whether unemployed individuals in the German-speaking region are more likely to find a new job by own initiative rather than by mediation of caseworkers in the regional labor offices. This provides direct evidence on the extent to which search effort exerted by the unemployed may account for regional unemployment differences. Second, we look at voting results from national referenda related to weekly working time, vacations, and/or early retirement. If the Latineffect is driven by cultural differences in norms and values, we should see differences in voting behavior not only between Latin- and German-speaking cantons but also at the language border within cantons. Finally, if culturally transmitted work norms are a first-order determinant of unemployment outcomes, we should see similar regional differences with respect to other dimensions of labor supply: labor force participation and full-time vs part time employment.

\subsection{Exit channels}

Our first step exploits information available in the AVAM database on how a new job was started: (i) whether this job was found by the unemployed worker him- or herself; or (ii) whether the new job was mediated by the caseworker at the local labor office. Studying the issue of how unemployed individuals find a new job sheds direct light on the job search effort of unemployed individuals.

Moreover, this analysis sheds further light on the issue whether differences in labor demand may explain the estimated Latin-effect. The idea is this: if unemployment differences are due to lower labor demand on the Latin side (because of job competition between migrants and natives or discrimination of Latin speaking Swiss-residents by all employers), this should show up in both exit channels. Firms are central both to jobs that job seekers locate themselves; and to jobs 
Table 6: The importance of various exit channels at the language barrier

\begin{tabular}{|c|c|c|c|c|}
\hline & (1) & $(2)$ & $(3)$ & (4) \\
\hline & All & Self & Empl. Serv. & Other \\
\hline & $96.21 \%$ & $48.30 \%$ & $14.47 \%$ & $33.44 \%$ \\
\hline \multirow[t]{2}{*}{ Latin } & $-0.322^{* * *}$ & $-0.497 * * *$ & $0.217^{* * *}$ & $-0.257^{* * *}$ \\
\hline & $(0.032)$ & $(0.047)$ & $(0.074)$ & $(0.042)$ \\
\hline \multirow{2}{*}{ Distance (100km) } & $0.0742^{* * *}$ & $0.157^{* * *}$ & -0.101 & 0.0548 \\
\hline & $(0.026)$ & $(0.040)$ & $(0.067)$ & $(0.040)$ \\
\hline \multirow[t]{2}{*}{ Distance-Latin } & 0.0105 & -0.0285 & 0.0263 & $0.0402^{*}$ \\
\hline & $(0.015)$ & $(0.027)$ & $(0.045)$ & $(0.022)$ \\
\hline All controls & Yes & Yes & Yes & Yes \\
\hline Observations & 173072 & 173072 & 173072 & 173072 \\
\hline \multicolumn{5}{|c|}{$\begin{array}{l}\text { Notes: Robust standard errors in parentheses. }{ }^{* * *} \mathrm{p}<0.01,{ }^{* *} \mathrm{p}<0.05,{ }^{*} \\
\mathrm{p}<0.1 \text {. Latin }=\text { majority in community speaks French, Italian or Romansh. } \\
\text { Distance = distance to language border (in } 100 \text { kilometers road distance). } \\
\text { All: all exits from unemployment. Self: exits to jobs found by the job seeker. } \\
\text { Empl. Serv.: exit to job found by the public employment service. Other: } \\
\text { destination unknown (job or non-employment). All controls as in table } 4 \text {. } \\
\text { Source: Data from Unemployment Register 1998-2003, Swiss Census } 2000 \text {, } \\
\text { Federal Statistical Office (FSO), CH-2010 Neuchatel. }\end{array}$} \\
\hline
\end{tabular}

that caseworkers at the employment office mediate. In contrast, job seekers are clearly central in locating jobs themselves, but their search effort is less crucial for jobs mediated by the public employment office. These jobs are assigned by caseworkers and job seekers who refuse to apply for such a job run into the risk that their benefits might be withheld. Hence strong regional differences in the relative importance of exits to own-initiative jobs and exits to caseworkermediated jobs make us more confident that cultural differences in work norms drive observed differences in unemployment durations.

Table 6 presents the results of our Cox proportional hazard rate analyses. Note that the dependent variable is no longer the duration of unemployment but the exit rate from unemployment. Hence the coefficients of Table 6 have a different interpretation than those in Table 4 . All models estimated in Table 6 control for the full set of variables (as in Table 4, column 4). Column 1 reports the estimates of the single-risk model, Columns 2 to 4 , report the estimates of a competing risk model with three exit states (own-initiative job, caseworker-mediated job; other exit). ${ }^{20}$ The estimate of the single-risk model in column 1 indicates that the overall exit

\footnotetext{
${ }^{20}$ This model assumes that the three competing exit hazards are independent conditional on information observed in the dataset. This allows separate estimation of the three hazard rates. We do not expect results on the Latin effect to be sensitive to the assumption of independence since these are identified from language border contrasts.
} 
rate is .322 log points lower on the Latin-speaking side than on the German-speaking side of the language border, consistent with our basic findings in Table 4. The estimates of the competing risk model yields a particularly interesting result. The barrier effect is extremely high for job finding rates on the unemployed worker's own initiative. The exit hazard rate is .497 log points (roughly 40 percent) lower on the Latin-speaking side compared to the German-speaking side. In contrast, the exit rate for jobs located by a local labor office is .217 log points (roughly 24 percent) higher on the Latin-speaking side compared to the German-speaking side of the language border. This could be due to the fact that there are more open vacancies on the Latin speaking side of the border compared to the German speaking side of the border (see Figure 6). The barrier effect for other exits is negative though only half as big as on exits to own-initiative jobs. This result is intuitive as other exits do not only include exits from the labor force, but also exits to own-initiative jobs that are not communicated to the local labor office. This lets us conclude that the Latin-effect for other exits might be a mixture between a negative effect for those that find a job themselves, and an insignificant effect for withdrawing from the labor force. Taken together we find that the relative importance of the way by which unemployed individuals find a new job changes strongly at the language border. This result is consistent with the hypothesis that observed unemployment differences are driven by cultural differences in job search behavior but are inconsistent with an explanation based on labor demand differences.

\section{$5.2 \quad$ Voting on work-times}

Our second step to look for the importance of cultural differences for unemployment is by reassessing regional differences in voting on work time regulations. Recall that Table 2 showed much stronger support for work time regulations in the Latin speaking areas of Switzerland than in the German speaking areas of Switzerland. If there is a cultural component explaining both voting and unemployment, then there should also be a gap in support for work time regulations at the language border. Figure 8 draws these voting results, using disaggregated information at the community level by distance to the language border.

Panel a)-c) show average (weighted) community votes for the referenda on working-time regulations ("intensive margin"), respectively for the 1985 vote whether to increase vacation weeks (panel a); and the 1988 and 2002 votes on a reduction of regular weekly working hours (panels b and c). These graphs tell a consistent story. In particular, there exists a large discontinuity in voting behavior at the language border. The voting population with residence on the Latin-speaking side of the language border votes also in favor of longer leisure as compared to the German-speaking side. The situation is very similar when we look at voting results concerning lifetime-work regulations. In panels d)-e) we see the results of the community votes on the 1988 vote on the reduction of the statutory retirement age, the 2000 vote on easier access to early retirement and the 2000 vote on leaving the retirement age for women at the current level (rather than increasing it). In all cases, we see the same consistent picture. Residents on the Latin-speaking side are much more in favor of leisure time than residents on the German- 
Figure 8: Voting results on 6 referenda, by distance to language border, Panels a)-f)

a. Vacations (1985)

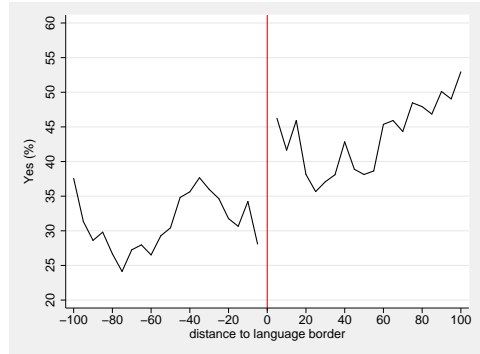

d. Retirement Age (1988)

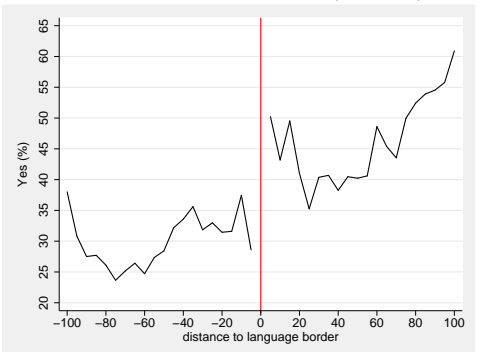

b. Work Hours (1988)

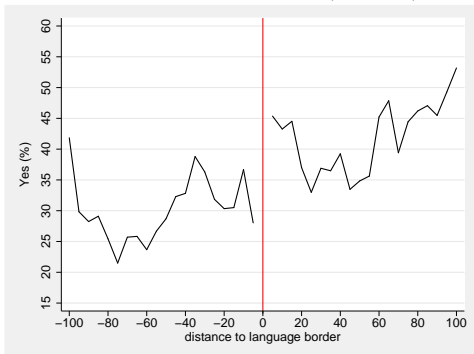

e. Retirement Age (2000)

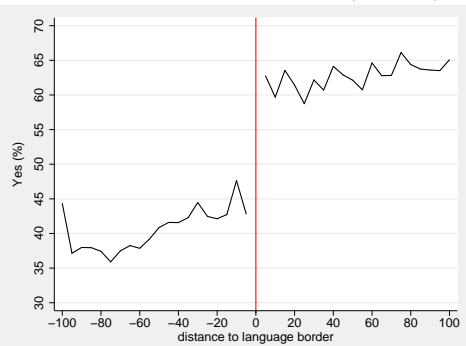

c. Work Hours (2002)

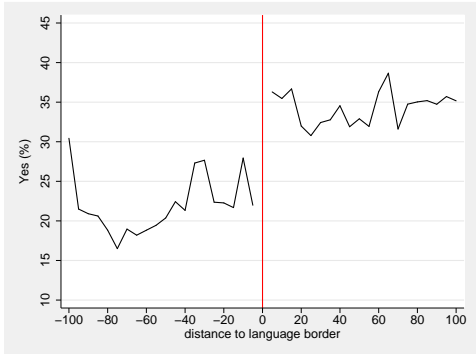

f. Women's Ret. Age (2000)

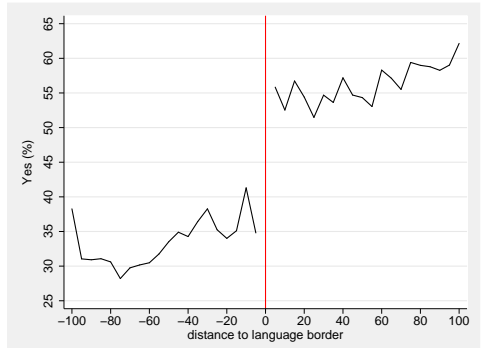

Notes: negative $=$ German-speaking part; positive=French-/Italian-speaking part. This figure reports percentage of yes votes in national referenda or voter initiatives on work time regulations.

Source: data from Federal Statistical Office (FSO), Neuchâtel.

speaking side. This evidence is consistent with strong language border differences in voting with respect to work time limits. Voting is of course endogenous taking into account the large differences in regional unemployment. Note, however, that in the late 1980s Switzerland was characterized by unemployment rates below the 1 percent level. Thus, even though there were still regional differences in unemployment, voters are likely to have been less concerned by the motive to generate employment for the unemployed. Nevertheless, we still find striking differences in voting on work time regulations for the 1980s votes. This suggests that there is a clear cultural break in attitudes towards work at the language border.

\subsection{Labor-supply gaps at the Röstigraben}

The third step to make a case for the importance of cultural differences in work attitudes is a look at other dimensions of labor supply. The idea is this: When cultural differences in attitudes towards work are a first-order explanatory factor behind observed differences in unemployment duration, we should see differences at the language border also with respect to other dimensions of labor supply. We use the Swiss population census of the year 2000 providing results on both Swiss men whose native language is a Swiss language and immigrants whose native language is not one of the four official Swiss languages. Public use files of this data set are unique as they provide information on the universe of the resident population in Switzerland. The large number of observations makes it an ideal data set to explore the issue. Our focus is labor force 
participation or, more precisely, a dummy indicating whether or not an individual is employed or unemployed (dummy takes value 1 ) or out of labor force (value 0$).{ }^{21}$

Table 7 provides results on unemployment duration, labor force participation, and full vs part-time employment for Swiss men who speak a Swiss language, and results for migrant men who do not speak a Swiss language, in the age bracket 16-64. Results consistently indicate that labor supply is lower on the Latin side of the language border compared to the German speaking side. Unemployment duration is 24 percent higher, labor force participation is 3 percentage points lower, and the rate of full time employment is 1 percent lower among residents of Latin border communities compared to what one would expect from German border communities. ${ }^{22}$ In contrast, labor supply of migrant men who do not speak a Swiss language does not differ in a statistically significant manner at the language border.

\section{Vertical versus horizontal cultural transmission}

The estimated Latin-effects in tables 4 to 5 are consistent with a large impact of culture on unemployment. In general any effects of culture are a mixture between an individual's culture inherited from the own family (vertical transmission) and the dominant culture of the individual's peers transmitted through social interaction, social networks, or social norms (horizontal transmission). That is, culture can be transmitted vertically from the parents to their children, but also horizontally from relevant peer groups. In this section we will disentangle these two transmission mechanisms using the fact that there is variation in native language within language regions. More precisely, there is a small (but non-negligible) fraction of individuals in the Latin region whose native language is German, and vice versa. Therefore we can separate the effect of being a Latin native speaker (vertical transmission) from the effect of living in a Latin community (horizontal transmission).

Table 8 shows the relative importance of vertical and horizontal transmission for unemployment duration. Column 1 of table 8 repeats the baseline estimation from table 4 , column 4 . Including a dummy for Latin native language into this regression (column 2) reduces the measured effect on the language border markedly. However, adding together the effect of vertical transmission (MT Latin) and horizontal transmission (Latin) yields an overall effect of culture quite similar to the one estimated in column 1. The coefficients of column 2 do not account for

\footnotetext{
${ }^{21}$ Using employment (rather than labor force participation) as a dependent variable does not change the results in Table 7. We also experimented with unemployment (both unconditional and conditional on being in the labor force) as the dependent variable. Also in the unemployment regressions results indicate higher unemployment probabilities in the Latin region. However, the year 2000 was a boom year with extremely low unemployment rates (below 1.5 percent in both language regions). This is why we prefer to look at labor force participation as the dependent variable.

${ }^{22}$ Focusing on bilingual cantons reproduces the same result. Further results (not shown) for labor market entrants (15-24 years), prime-age workers (25-49 years), and labor market leavers (50-64 years) indicate that labor force participation is more strongly reduced among entrants and leavers whereas the reduction of fulltime employment occurs among prime-age workers. Unemployment results also indicate a stronger effect among younger age groups (25-49 years) than for older cohorts (50-59 years).
} 
Table 7: Unemployment Duration and Labor Force Participation

\begin{tabular}{|c|c|c|c|c|c|c|}
\hline \multirow[b]{3}{*}{ Dependent variable } & \multicolumn{3}{|c|}{$\begin{array}{c}\text { Swiss men } \\
\text { (Swiss native language) }\end{array}$} & \multicolumn{3}{|c|}{$\begin{array}{c}\text { Migrant men } \\
\text { (non-Swiss native language) }\end{array}$} \\
\hline & $(1)$ & $(2)$ & $(3)$ & $(4)$ & (5) & (6) \\
\hline & $\begin{array}{c}\log \\
\text { duration }\end{array}$ & $\begin{array}{c}\text { in labor } \\
\text { force }\end{array}$ & $\begin{array}{l}\text { full-time } \\
\text { employed }\end{array}$ & $\begin{array}{c}\log \\
\text { duration }\end{array}$ & $\begin{array}{c}\text { in labor } \\
\text { force }\end{array}$ & $\begin{array}{l}\text { full-time } \\
\text { employed }\end{array}$ \\
\hline \multirow[t]{2}{*}{ Latin } & $0.215^{* * *}$ & $-0.0311^{* * *}$ & $-0.0115^{* * *}$ & 0.0674 & -0.0123 & -0.00543 \\
\hline & $(0.031)$ & $(0.00333)$ & $(0.00353)$ & $(0.052)$ & $(0.0112)$ & $(0.00597)$ \\
\hline \multirow[t]{2}{*}{ Distance (100km) } & $-0.0948^{* * *}$ & -0.00364 & -0.00153 & -0.0138 & 0.000363 & $-0.00908^{*}$ \\
\hline & $(0.028)$ & $(0.00370)$ & $(0.00423)$ & $(0.047)$ & $(0.00806)$ & $(0.00529)$ \\
\hline \multirow[t]{2}{*}{ Distance-Latin } & 0.00205 & $0.0201^{* * *}$ & $0.0146^{* *}$ & -0.00653 & 0.000660 & 0.00571 \\
\hline & $(0.014)$ & $(0.00647)$ & $(0.00725)$ & $(0.021)$ & $(0.0139)$ & $(0.00975)$ \\
\hline \multirow[t]{2}{*}{ Constant } & $2.363^{* * *}$ & $0.946^{* * *}$ & $0.833^{* * *}$ & $2.942^{* * *}$ & $0.765^{* * *}$ & $0.927^{* * *}$ \\
\hline & $(0.224)$ & $(0.0206)$ & $(0.0302)$ & $(0.467)$ & $(0.127)$ & $(0.0506)$ \\
\hline All controls & Yes & Yes & Yes & Yes & Yes & Yes \\
\hline Observations & 173072 & 1718501 & 1445747 & 99093 & 198150 & 150331 \\
\hline$R^{2}$ & 0.126 & 0.212 & 0.061 & 0.098 & 0.083 & 0.023 \\
\hline
\end{tabular}

Notes: Standard errors in parentheses. ${ }^{* * *} \mathrm{p}<0.01$, ${ }^{* *} \mathrm{p}<0.05,{ }^{*} \mathrm{p}<0.1$. Latin = majority in community speaks French, Italian or Romansh. Distance $=$ distance to language border (in 100 kilometers road distance). Source: Data from Swiss Census 2000, Federal Statistical Office (FSO), CH-2010 Neuchatel.

the fact that it could be harder to find a job in a region where you do not speak the dominant local language. Therefore columns 3 and 4 repeat the analysis of columns 1 and 2 including a dummy indicating whether the individual's native language differs from the dominant local language. The estimated culture-effects do not change at all. Note, however, that our estimate of having a native language that differs from the local language is surprisingly negative (though relatively small). This could be a sign for a positive selection of individuals moving to the other language region. Column 5 of table 8 takes into account that the percentage of Latin speakers does not increase from $0 \%$ to $100 \%$ at the language border. That is, we deal with a fuzzy RD design. Using a standard two stage procedure, we can extrapolate the effect on unemployment duration that would arise when changing the percentage Latin speakers from $0 \%$ to $100 \%$. The results suggest that increasing the percentage of Latin speakers by $100 \%$ prolongs unemployment duration by $17 \%$. In contrast, interacting with Latin speaking parents increases unemployment duration $10 \%$. This suggests that vertical transmission of culture is about half as important as horizontal transmission of culture in explaining unemployment duration.

To check the robustness of our estimates further, table 9 takes a closer look at the effect of 
Table 8: Separating Horizontal and Vertical Transmission of Culture

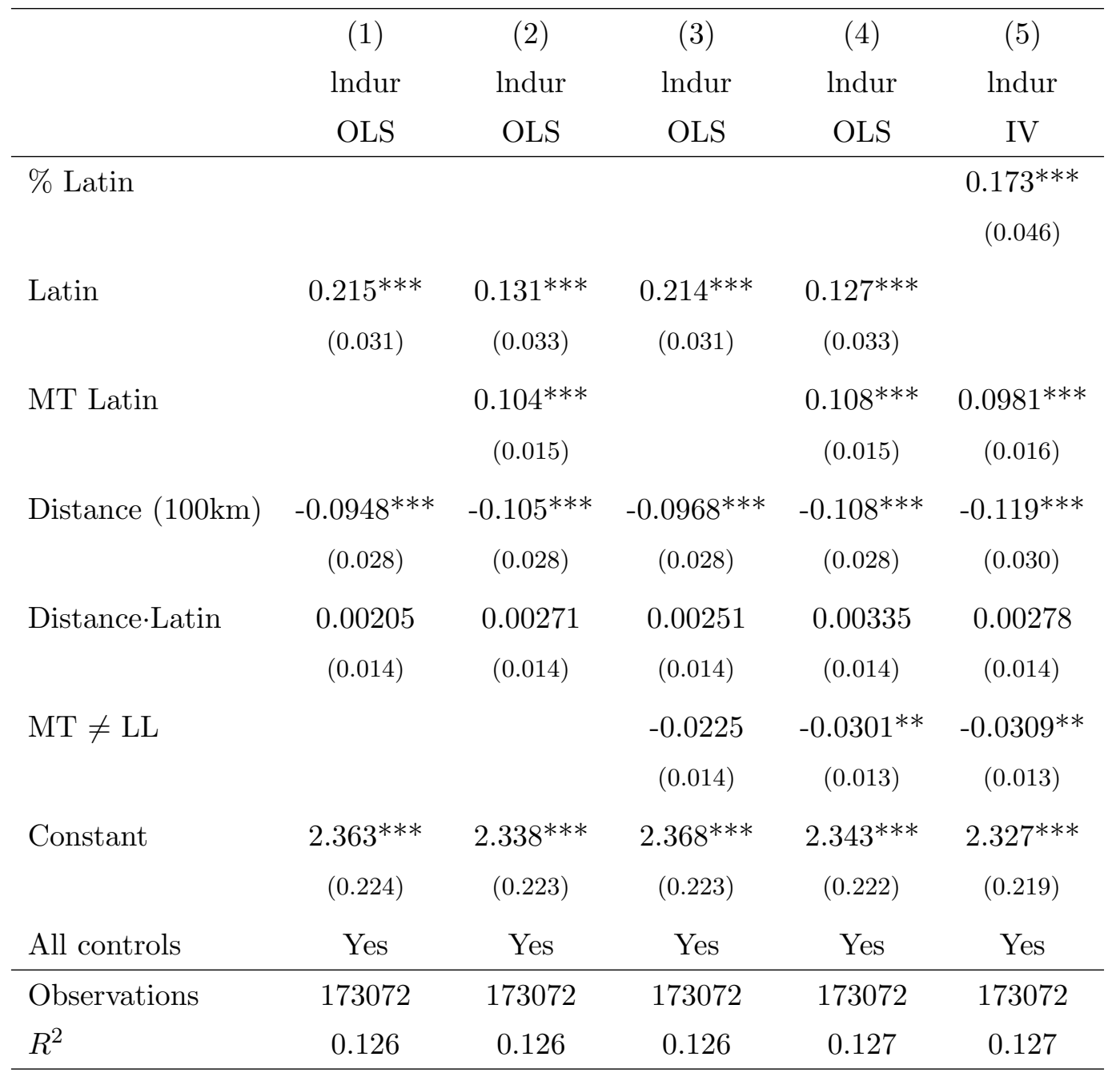

Notes: Robust standard errors in parentheses. ${ }^{* * *} \mathrm{p}<0.01,{ }^{* *} \mathrm{p}<0.05,{ }^{*} \mathrm{p}<0.1$. Latin $=$ majority in community speaks French, Italian or Romansh. Distance $=$ distance to language border (in 100 kilometers road distance). MT Latin = native language is French, Italian, or Romansh. $\mathrm{MT} \neq \mathrm{LL}=$ native language is different from community majority language. All controls as in table 4.

Source: Data from Unemployment Register 1998-2003, Swiss Census 2000, Federal Statistical Office (FSO), CH-2010 Neuchatel.

vertical transmission of culture. Column 1 of table 9 repeats column 4 of table 8 . Columns 2 of table 9 looks more closely on the isolated effect of vertical transmission (own native language) using a design where horizontal transmission is captured by community fixed effects. It turns out that the estimate of vertically transmitted culture does not differ from our estimate of column 1. Column 3 estimates the same model using only data from the three bilingual cantons (Berne, Valais, and Fribourg). This yields results very similar to the baseline specification of column 1, though within bilingual cantons the vertical transmission effect at the language border becomes somewhat more important. In column 4 we confine the analysis to observations from the city of Fribourg only. Fribourg is an interesting case because it is a bilingual city (with some 
more Latin-speaking than German-speaking individuals). People living in Fribourg share the same environment and the same labor market, independently of their native language and as a result of bilinguality there is no obvious disadvantage speaking a Latin or the German language. Therefore we can estimate the effect of vertical transmission very comprehensively in this city. It turns out that the vertical transmission within the city of Fribourg is on the same order of magnitude than the corresponding effect estimated using data from whole Switzerland. This evidence is consistent with adaptation eroding little of the values transmitted from parents to children. Finally, in columns 5 and 6 of table 9 we look at the Latin and the German region separately. The vertical transmission effect is identified contrasting natives and non-natives in the Latin region (presumably leading to a downward bias if there is a native advantage), and the native language effect is identified contrasting non-native Latin speakers with German natives (leading to an upward bias). Thus, strong asymmetries in the native language effect (being Latin native-speaker causes a labor market disadvantage) would indicate failure of identification. It turns out that the estimated effect of being Latin native speaker is not statistically significantly different and quantitatively very similar in both language regions. This is consistent with the key identifying assumption that there are no unobserved differences between movers and stayers (see section 3).

To learn more about the relative importance of horizontal versus vertical transmission of culture we look in more detail at the exit process from unemployment to a regular job. Using exit-channel information available in the AVAM data, we now extend our analysis of table 6 above. In particular, we study whether an individual's own native language affects exit channels (own-initiative jobs versus caseworker-mediated jobs) in a different way than the dominant language of the resident community. Column 1 of Table 10 shows the result of the single-risk analysis adding a Latin native-speaker dummy as a proxy for vertical transmission of culture. Columns 2 to 4 show the results from the competing risk analysis with exit channel own-initiative job (column 2), caseworker-mediated job (column 3) and other exits (column 4). (Notice that coefficients indicate the estimated effect on the exit rate, hence signs are different from previous tables using unemployment durations as the dependent variable). The estimated effects confirm our previous results. The single-risk analysis of column 1 shows that both horizontal and vertical transmissions effects are (statistically and quantitatively) highly significant with the horizontal channel being somewhat more important. More interestingly, we find that the effect is driven by exits to own-initiative job. Both Latin-effects, own language and language region, are significantly negative. Interestingly, being Latin-native speaker also reduces the probability of leaving the unemployment register via "other exits". This result can be rationalized as follows: Our sample consists of prime-age Swiss males, a group that is most likely in the labor force and unlikely to leave the labor force. Hence "other exits" are mainly exits to jobs that are not reported to the local labor office. By definition, only own-initiative jobs are not reported to the local labor office. Hence in this respect it is not surprising to see a negative impact of Latin language also in this dimension. ${ }^{23}$

\footnotetext{
${ }^{23}$ We also estimated Cox regressions that are stratified at the community level. These compare with the fixed
} 
Table 9: Sensitivity Analysis on Vertical vs Horizontal Transmission

\begin{tabular}{|c|c|c|c|c|c|c|}
\hline & $\begin{array}{c}(1) \\
\text { OLS }\end{array}$ & $\begin{array}{c}(2) \\
\text { Community } \\
\text { FE }\end{array}$ & $\begin{array}{c}(3) \\
\text { Bilingual } \\
\text { cantons }\end{array}$ & $\begin{array}{c}(4) \\
\text { Fribourg }\end{array}$ & $\begin{array}{l}(5) \\
\text { Latin } \\
\text { region }\end{array}$ & $\begin{array}{c}(6) \\
\text { German } \\
\text { region }\end{array}$ \\
\hline Latin & $\begin{array}{c}0.127^{* * *} \\
(0.033)\end{array}$ & & $\begin{array}{c}0.114^{* *} \\
(0.046)\end{array}$ & & & \\
\hline MT Latin & $\begin{array}{c}0.108^{* * *} \\
(0.015)\end{array}$ & $\begin{array}{c}0.106^{* * *} \\
(0.017)\end{array}$ & $\begin{array}{c}0.147^{* * *} \\
(0.034)\end{array}$ & $\begin{array}{c}0.107^{* *} \\
(0.008)\end{array}$ & $\begin{array}{c}0.101^{* * *} \\
(0.021)\end{array}$ & $\begin{array}{c}0.0852^{* * *} \\
(0.022)\end{array}$ \\
\hline Distance $(100 \mathrm{~km})$ & $\begin{array}{c}-0.108^{* * *} \\
(0.028)\end{array}$ & & $\begin{array}{l}-0.125 \\
(0.081)\end{array}$ & & & \\
\hline Distance.Latin & $\begin{array}{c}0.00335 \\
(0.014)\end{array}$ & & $\begin{array}{c}-0.0447 \\
(0.139)\end{array}$ & & & \\
\hline $\mathrm{MT} \neq \mathrm{LL}$ & $\begin{array}{c}-0.0301^{* *} \\
(0.013)\end{array}$ & $\begin{array}{c}-0.0180 \\
(0.013)\end{array}$ & $\begin{array}{c}0.00795 \\
(0.022)\end{array}$ & & & \\
\hline Constant & $\begin{array}{c}2.343^{* * *} \\
(0.222)\end{array}$ & $\begin{array}{c}3.337^{* * *} \\
(0.546)\end{array}$ & $\begin{array}{c}1.475^{* * *} \\
(0.456)\end{array}$ & $\begin{array}{c}5.248^{* *} \\
(0.086)\end{array}$ & $\begin{array}{c}3.251^{* * *} \\
(0.307)\end{array}$ & $\begin{array}{c}2.237^{* * *} \\
(0.416)\end{array}$ \\
\hline All controls & Yes & Yes & Yes & Yes & Yes & Yes \\
\hline Observations & 173072 & 173072 & 34528 & 684 & 52317 & 120755 \\
\hline$R^{2}$ & 0.127 & 0.086 & 0.101 & 0.125 & 0.120 & 0.105 \\
\hline
\end{tabular}

Notes: Robust standard errors in parentheses. ${ }^{* * *} \mathrm{p}<0.01,{ }^{*} \mathrm{p}<0.05,{ }^{*} \mathrm{p}<0.1$. Latin $=$ majority in community speaks French, Italian or Romansh. Distance = distance to language border (in 100 kilometers road distance). MT Latin = native language is French, Italian, or Romansh. MT $\neq$ LL = native language is different from community majority language. All controls as in table 4. Source: Data from Unemployment Register 1998-2003, Swiss Census 2000, Federal Statistical Office (FSO), CH-2010 Neuchatel.

Do the baseline estimates of the Latin region and Latin mother tongue effects merely reflect past experiences of unemployment? To check whether this concern is important we use information on the individual's past unemployment history available in the AVAM data. In particular, Table 11 splits the sample into individuals who are experiencing their first unemployment spell in the last 5 years and individuals who have experienced one or more spells in the last 5 years before their current unemployment spell. ${ }^{24}$

Column 1 of table 11 repeats the baseline result of table 8 (column 4). Columns 2 and 3 repeat this same regression when the sample is confined to individuals without a previous unemployment

effects regression from table 9 in that they allow for differences in the baseline hazard by communities. Comparing the stratified estimates to columns 1-4 in Table 10 we find no noteworthy differences in the estimated effect of vertical transmission of culture on exit rates.

${ }^{24}$ Notice that we have data on unemployment history back to 1993 , therefore we can identify the exact number of spells in the last five years for every unemployment spell in the data set. 
Table 10: Exit channels and Horizontal vs Vertical Transmission of Culture

\begin{tabular}{|c|c|c|c|c|}
\hline & (1) & $(2)$ & (3) & (4) \\
\hline & All & Self & Empl. Serv. & Other \\
\hline & $96.21 \%$ & $48.30 \%$ & $14.47 \%$ & $33.44 \%$ \\
\hline \multirow[t]{2}{*}{ Latin } & $-0.229^{* * *}$ & $-0.390 * * *$ & $0.173^{* *}$ & $-0.129^{* * *}$ \\
\hline & $(0.033)$ & $(0.048)$ & $(0.079)$ & $(0.047)$ \\
\hline \multirow[t]{2}{*}{ MT Latin } & $-0.118^{* * *}$ & $-0.135^{* * *}$ & 0.0579 & $-0.162^{* * *}$ \\
\hline & $(0.013)$ & $(0.021)$ & $(0.035)$ & $(0.023)$ \\
\hline \multirow[t]{2}{*}{ Distance $(100 \mathrm{~km})$} & $0.0877^{* * *}$ & $0.171^{* * *}$ & -0.107 & $0.0758^{*}$ \\
\hline & $(0.026)$ & $(0.040)$ & $(0.067)$ & $(0.040)$ \\
\hline \multirow[t]{2}{*}{ Distance-Latin } & 0.0100 & -0.0294 & 0.0258 & $0.0388^{*}$ \\
\hline & $(0.015)$ & $(0.027)$ & $(0.045)$ & $(0.022)$ \\
\hline \multirow[t]{2}{*}{$\mathrm{MT} \neq \mathrm{LL}$} & $0.0226^{* *}$ & 0.0115 & -0.000654 & $0.0626^{* * *}$ \\
\hline & $(0.011)$ & $(0.016)$ & $(0.028)$ & $(0.017)$ \\
\hline All controls & Yes & Yes & Yes & Yes \\
\hline Observations & 173072 & 173072 & 173072 & 173072 \\
\hline \multicolumn{5}{|c|}{$\begin{array}{l}\text { Notes: Robust standard errors in parentheses. }{ }^{* * *} \mathrm{p}<0.01,{ }^{* *} \mathrm{p}<0.05,{ }^{*} \mathrm{p}<0.1 . \\
\text { Latin = majority in community speaks French, Italian or Romansh. Distance }= \\
\text { distance to language border (in } 100 \text { kilometers road distance). MT Latin = native } \\
\text { language is French, Italian, or Romansh. MT } \neq \mathrm{LL}=\text { native language is different from } \\
\text { community majority language. All: all exits from unemployment. Self: exits to jobs } \\
\text { found by the job seeker. Empl. Serv.: exit to job found by the public employment } \\
\text { service. Other: destination unknown (job or non-employment). Stratification at } \\
\text { the community level. All controls as in table } 4 \text {. Source: Data from Unemployment } \\
\text { Register 1998-2003, Swiss Census 2000, Federal Statistical Office (FSO), CH-2010 }\end{array}$} \\
\hline
\end{tabular}


Table 11: The Role of Prior Unemployment Experience

\begin{tabular}{|c|c|c|c|c|c|c|}
\hline & $\begin{array}{c}(1) \\
\text { lndur } \\
\text { All }\end{array}$ & $\begin{array}{c}(2) \\
\text { lndur } \\
1^{\text {st }} \text { spell }\end{array}$ & $\begin{array}{c}(3) \\
\operatorname{lndur} \\
\text { not } 1^{\text {st }} \text { spell }\end{array}$ & $\begin{array}{c}(4) \\
\text { lndur } \\
\text { not } 1^{\text {st }} \text { spell }\end{array}$ & $\begin{array}{c}(5) \\
\text { lndur } \\
\text { not } 1^{\text {st }} \text { spell }\end{array}$ & $\begin{array}{c}(6) \\
\operatorname{lndur} \\
\text { not } 1^{\text {st }} \text { spell }\end{array}$ \\
\hline Latin & $\begin{array}{c}0.127^{* * *} \\
(0.033)\end{array}$ & $\begin{array}{c}0.183^{* * *} \\
(0.041)\end{array}$ & $\begin{array}{c}0.104^{* *} \\
(0.041)\end{array}$ & $\begin{array}{c}0.0984^{* *} \\
(0.040)\end{array}$ & $\begin{array}{c}0.0894^{* *} \\
(0.041)\end{array}$ & $\begin{array}{c}0.0842^{* *} \\
(0.040)\end{array}$ \\
\hline MT Latin & $\begin{array}{c}0.108^{* * *} \\
(0.015)\end{array}$ & $\begin{array}{c}0.110^{* * *} \\
(0.021)\end{array}$ & $\begin{array}{c}0.107^{* * * *} \\
(0.021)\end{array}$ & $\begin{array}{c}0.108^{* * *} \\
(0.021)\end{array}$ & $\begin{array}{c}0.0955^{* * *} \\
(0.021)\end{array}$ & $\begin{array}{c}0.0964^{* * *} \\
(0.021)\end{array}$ \\
\hline Distance $(100 \mathrm{~km})$ & $\begin{array}{c}-0.108^{* * *} \\
(0.028)\end{array}$ & $\begin{array}{c}-0.109 * * * \\
(0.031)\end{array}$ & $\begin{array}{c}-0.103^{* * *} \\
(0.037)\end{array}$ & $\begin{array}{c}-0.0959^{* * *} \\
(0.037)\end{array}$ & $\begin{array}{c}-0.0959^{* * *} \\
(0.037)\end{array}$ & $\begin{array}{c}-0.0890^{* *} \\
(0.036)\end{array}$ \\
\hline Distance-Latin & $\begin{array}{l}0.00335 \\
(0.014)\end{array}$ & $\begin{array}{l}0.0109 \\
(0.019)\end{array}$ & $\begin{array}{c}-0.000242 \\
(0.020)\end{array}$ & $\begin{array}{c}-0.000456 \\
(0.020)\end{array}$ & $\begin{array}{c}-0.00269 \\
(0.020)\end{array}$ & $\begin{array}{c}-0.00290 \\
(0.020)\end{array}$ \\
\hline $\mathrm{MT} \neq \mathrm{LL}$ & $\begin{array}{c}-0.0301 * * \\
(0.013)\end{array}$ & $\begin{array}{l}-0.0213 \\
(0.016)\end{array}$ & $\begin{array}{c}-0.0327^{*} \\
(0.018)\end{array}$ & $\begin{array}{c}-0.0315^{*} \\
(0.017)\end{array}$ & $\begin{array}{c}-0.0311^{*} \\
(0.018)\end{array}$ & $\begin{array}{c}-0.0298^{*} \\
(0.017)\end{array}$ \\
\hline No. of spells last 5 years & & & & $\begin{array}{c}-0.0587^{* * *} \\
(0.003)\end{array}$ & & $\begin{array}{c}-0.0588^{* * *} \\
(0.003)\end{array}$ \\
\hline Avg. log dur last 5 years & & & & & $\begin{array}{c}0.0693^{* * *} \\
(0.004)\end{array}$ & $\begin{array}{c}0.0693 * * * \\
(0.004)\end{array}$ \\
\hline Constant & $\begin{array}{c}2.343^{* * *} \\
(0.222)\end{array}$ & $\begin{array}{c}2.871^{* * *} \\
(0.316)\end{array}$ & $\begin{array}{c}2.294^{* * *} \\
(0.290)\end{array}$ & $\begin{array}{c}2.569^{* * *} \\
(0.282)\end{array}$ & $\begin{array}{c}1.905^{* * *} \\
(0.288)\end{array}$ & $\begin{array}{c}2.180^{* * *} \\
(0.280)\end{array}$ \\
\hline All controls & Yes & Yes & Yes & Yes & Yes & Yes \\
\hline Observations & 173072 & 72034 & 101038 & 101038 & 101038 & 101038 \\
\hline$R^{2}$ & 0.127 & 0.174 & 0.107 & 0.111 & 0.110 & 0.114 \\
\hline
\end{tabular}

Notes: Robust standard errors in parentheses. ${ }^{* * *} \mathrm{p}<0.01,{ }^{* *} \mathrm{p}<0.05,{ }^{*} \mathrm{p}<0.1$. Latin = majority in community speaks French, Italian or Romansh. Distance = distance to language border (in 100 kilometers road distance). MT Latin = native language is French, Italian, or Romansh. MT $\neq$ LL = native language is different from community majority language. No. of spells last 5 years: Number of unemployment spells in the 5 years prior to this spell. Avg. log dur last 5 years: Average log duration of unemployment spells in the 5 years prior to this unemployment spell. All controls as in table 4. Source: Data from Unemployment Register 1998-2003, Swiss Census 2000, Federal Statistical Office (FSO), CH-2010 Neuchatel.

spell in the recent past (column 2) and individuals with one or more previous spells (column 3). It turns out that the Latin-region effect is even stronger among individuals experiencing their first unemployment spell and lower for individuals with previous unemployment experience. We do not see a significant difference of Latin native-language effect between groups with a different unemployment background. This means that vertical transmission of culture is not driven by past unemployment history. In contrast, the horizontal cultural channel is sensitive to the experience of unemployment.

Columns 4 to 6 of table 11 elaborate further on the role of previous employment history for repeatedly unemployed job seekers. Column 4 adds information on the number of unemployment spells. Interestingly, both the native language and Latin region effect remain unaffected by 
adding controls for unemployment recurrence suggesting that there are no important differences in terms of past unemployment recurrence between both Latin region and German region residents, and Latin speakers compared to German speakers. Column 4 adds average duration of unemployment spells in the past. Interestingly, both the vertical and the horizontal transmission of culture channel are slightly lower compared to the baseline in column 3 that does not control for past duration. This suggests that there are indeed differences in past unemployment duration. Importantly, these differences do in no way account for the salient and strong differences in unemployment duration between Latin speakers and German speakers, and Latin region residents compared to their German region counterparts. Column 6 adds both past unemployment recurrence and mean duration to the main regression model. Results indicate that both vertical and horizontal transmission of culture remain statistically highly significant and quantitatively important. ${ }^{25}$ We conclude that the Latin-effects (regional and own language) are quantitatively important and not driven by differential unemployment histories between Latin and German native speakers and Latin and German language regions.

\section{Conclusions}

This paper analyzes the role of culture in explaining unemployment duration along the Swiss Röstigraben - the language barrier separating the German-speaking from the Latin-speaking (i.e. French- and Italian-speaking) regions of Switzerland. Our strategy to identify an effect of culture on unemployment relies on the idea that, while the Röstigraben separates cultural groups, it neither separates labor markets nor political jurisdictions. This idea is tested in various steps. We first collect data on national votes in Switzerland that are associated with limiting work time (weekly hours, duration of vacancies, and early retirement). We argue that voting results are proxies of tastes for leisure. The data do not only indicate a strikingly higher support for work limits on the Latin-side of the Röstigraben. (The percentage of votes in 6 national referenda on work-time limits was between 13 to 23 percentage points higher - or 1.4 to 1.7 as large - in Latin-speaking regions as compared to German-speaking regions.). The voting support also changes to a similar extent at the language border.

Second, to the extent that the language border is associated with a change in attitudes towards work and tastes for leisure, the Röstigraben lends itself to studying culture because important segments of that border do not coincide with the borders of Swiss states. Hence, with such quasi-experimental variation in tastes for leisure at the language barrier we can identify the role of culture in explaining unemployment. We discuss in detail how alternative explanations might contribute to the unemployment-gap at the Röstigraben and find that this gap is unlikely generated by differences in labor market conditions and/or changes in political jurisdictions. We also find that differences in labor market policies cannot account for the discontinuous change

\footnotetext{
${ }^{25}$ Consistent with the previous literature, we find that longer durations in the past are associated with longer current unemployment; and more spells in the past go hand in hand with shorter spells in the present (indicating instable employment, i.e. frequent moves between employment and unemployment).
} 
in unemployment at the Röstigraben.

As a third way to test for potential importance of different tastes for leisure we exploit information in Swiss unemployment register data about the way unemployed individuals find a new job (by own initiative versus by mediation through local labor offices). Results indicate that the bulk of the difference is driven by a lower exit rate to own-initiative jobs on the Latin-speaking side. Finally, we document that individuals on the Latin-side do not only have higher unemployment durations but there is also a gap in other dimensions of labor supply. In particular, our findings indicate a substantial Röstigraben-gap in labor force participation rates, which is particularly large for younger and older individuals.

Our analysis also sheds light on the relative importance of horizontal versus vertical transmission of culture. In this dimension we go beyond the epidemiological literature that has concentrated on the vertical transmission mechanism (Fernández and Fogli, 2006, Fernández, 2007). As we observe individuals in the Latin region whose native language is German, and vice versa, we can separate the effect of being a Latin native speaker (vertical transmission) from the effect of living in a Latin community (horizontal transmission). We find that both channels are of substantial importance, with the horizontal effect being roughly twice as large as the vertical effect.

In quantitative terms, our analysis suggests that culture is an important predictor of unemployment. Our horizontal estimate suggests that a change in the cultural environment from a 0 percent to a 100 percent Latin neighborhood increases unemployment durations by .173 log points; and our vertical transmission estimate suggests that being Latin (rather than German) native speaker increases the duration of unemployment by .098 log points. Evaluated at the sample mean, the overall effect of culture is on the order of a 7 weeks difference in the average duration of unemployment. Quantitatively, this is a very large effect. Taking as a benchmark the estimate of Katz and Meyer (1990) - according to which a 10 weeks increase in maximum benefit duration increases the average duration of unemployment by 1 week - our estimates suggest that our estimated culture-effect is as large as the effect of a 1.3 years (!) increase in maximum benefit duration.

Clearly, the "change culture" policy cannot be mandated whereas the "change unemployment benefit generosity" policy can be. Does this mean that our results are irrelevant to economic policy? We believe that the answer is no, for at least three reasons. First, our research sheds light on the reasons for the tremendous differences in regional unemployment rates that have puzzled policy makers and researchers for a long time. Second, having identified the role of cultural differences in explaining unemployment we can now start thinking about how economic policy interacts with culture. Third, cultural differences may also give rise to different policies. Understanding the reverse arrow of causation is a further topic of future research. 


\section{References}

[1] Alesina, Alberto, Edward Glaeser, and Bruce Sacerdote (2006), Work and Leisure in the U.S. and Europe. Why so Different? NBER Macroeconomics Annual (eds. M.Gertler and K.Rogoff)

[2] Alesina, Alberto and Nicola Fuchs-Schündeln (2007), Good-Bye Lenin (or Not?): The Effect of Communism on People's Preferences, American Economic Review, 97, 1507-1528

[3] Alesina, Alberto and Paola Giuliano (2007), The Power of the Family, IZA Discussion Paper No 2750 .

[4] Algan, Y. and P. Cahuc (2005) "The Roots of Low European Employment: Family Culture?" NBER International Seminar on Macroeconomics, MIT Press (eds J. Frenkel and C. Pissarides).

[5] Algan Y. and P. Cahuc (2009) "Civic Culture and the Design of Labor Market institutions" American Economic Journal: Macroeconomics 1(1): 111-145.

[6] Aspachs-Bracons, Oriol, Costa-Font, Joan, Clots, Irma and Masella, Paolo (2008). "Compulsory Language Educational Policies And Identity Formation", Journal of the European Economic Association 6(2-3): 434-444.

[7] Bisin, A., Verdier, T., (2000), “Beyond the Melting Pot': Cultural Transmission, Marriage and the Evolution of Ethnics and Religious Traits", Quarterly Journal of Economics, Vol. 115, No. 3, 955-988.

[8] Bisin, A., Verdier, T., (2001), "The Economics of Cultural Transmission and the Dynamics of Preferences", Journal of Economic Theory, 97, 298-319.

[9] Bisin, A., Topa, G., Verdier, T., (2004), "Religious Intermarriage and Socialization in the United States", Journal of Political Economy, Vol. 112, No. 3, 615-664.

[10] Büchi, Christophe (2003), Röstigraben. Das Verhältnis ziwschen deutscher und französischer Schweiz. Geschichte und Perspektiven, Verlag Neue Zürcher Zeitung.

[11] Calvo-Armengol, Antonio and Jackson, Mathew, (2004). The Effects of Social Networks on Employment and Inequality, American Economic Review, 94(3), 426-454.

[12] Clark, Andrew (2003). "Unemployment as a Social Norm: Psychological Evidence from Panel Data", Journal of Labor Economics, 21, pp.323-351.

[13] Diekmann, Andreas, Engelhardt, Henriette, Jann, Benn, Armigeon, Klaus and Geissbühler, Simon (1998). "Der Schweizer Arbeitsmarktsurvey", University of Berne.

[14] Doepke M. and F. Zilibotti (2008) "Occupational Choice and the Spirit of Capitalism", Quarterly Journal of Economics, 123(2): 747-793. 
[15] Fernández, R. (2007). Women, work, and culture. Journal of the European Economic Association 5(2-3): 305-332.

[16] Fernández, R. and Fogli, A. (2009). Culture: an empirical investigation of beliefs, work and fertility. American Economic Journal: Macroeconomics 1(1): 146-177.

[17] Fernández, R. and Fogli, A. (2006). Fertility: the role of culture and family experience. Journal of the European Economic Association 4, 552-61.

[18] Frölich, Markus and Lechner, Michael, 2004. "Regional Treatment Intensity as an Instrument for the Evaluation of Labour Market Policies," IZA Discussion Papers 1095.

[19] Gerfin Michael and Michael Lechner, 2002. "A Microeconometric Evaluation of the Active Labour Market Policy in Switzerland," Economic Journal 112: 854-893.

[20] Guiso, L., P. Sapienza and Zingales, L. (2009). Cultural biases in economic exchange. Quarterly Journal of Economics forthcoming.

[21] Guiso, L., Sapienza, P. and Zingales, L. (2006). Does culture affect economic outcomes? Journal of Economic Perspectives 20(2), 23-48.

[22] Hahn, J., Todd, P., and van der Klaauw, W. (2001). Identification and Estimation of Treatment Effects with a Regression-Discontinuity Design. Econometrica, 69(1), 201-209.

[23] Hauk, Esther and Saez-Marti, Maria, 2002. "On the Cultural Transmission of Corruption," Journal of Economic Theory, 107(2), pages 311-335, December.

[24] European and World Values Surveys four-wave integrated data file, 1981-2004, v.20060423, 2006. Surveys designed and executed by the European Values Study Group and World Values Survey Association. File Producers: ASEP/JDS, Madrid, Spain and Tilburg University, Tilburg, the Netherlands. File Distributors: ASEP/JDS and GESIS, Cologne, Germany.

[25] Ichino, A. and G. Maggi (2000), "Work Environment and Individual Background: Explaining Regional Shirking Differentials in a Large Italian Firm," Quarterly Journal of Economics 115: 1057-1090.

[26] Katz, L. and Meyer, B. (1990), "The Impact of the Potential Duration of Unemployment Benefits on the Duration of Unemployment", Journal of Public Economics, 41, 45-72.

[27] Kolm, Ann-Sofie (2005). "Work Norms and Unemployment", Economics Letters, vol. 88(3), 426-431.

[28] Lalive Rafael, Jan C. van Ours and Josef Zweimüller, 2005. "The Effect Of Benefit Sanctions On The Duration Of Unemployment," Journal of the European Economic Association 3: 1386-1417. 
[29] Lindbeck, Assar and Sten Nyberg (2006). "Raising Children to Work Hard: Altruism, Work Norms and Social Insurance", Quarterly Journal of Economics, 121: 1473-1503.

[30] Lindbeck, Assar, Sten Nyberg, and Jörgen Weibull (2003) "Social Norms and Welfare State Dynamics", Journal of the European Economic Association , 1(2-3), April-May 2003, 533542 .

[31] Lüdi Georges and Iwar Werlen (2005). Sprachenlandschaft in der Schweiz, Eidgenössische Volkszählung 2000, Bundesamt für Statistik, Neuchatel.

[32] Nickell, Stephen and Richard Layard (1999) "Labor market institutions and economic performance", Handbook of Labor Economics, 3, 3029-3084.

[33] Novembre, John, Johnson, Toby, Bryc, Katarzyna, Kutalik, Zoltan, Boyko, Adam R. Auton, Adam, Indap, Amit, King, Karen S., Bergmann, Sven, Nelson, Matthew R., Stephens, Matthew, Bustamante, Carlos D. (2008), "Genes mirror geography within Europe", Nature, 456(7218): 98-101.

[34] OECD (2005). "Employment Outlook". OECD: Paris.

[35] Prescott E. C. (2004) "Why Do Americans Work So Much More Than Europeans?" Federal Reserve Bank of Minneapolis Quarterly Review, Vol. 28, No. 1, July 2004, pp.2-13.

[36] Stutzer, A. and Lalive, R. (2004). The Role of Social Norms in Job Searching and Subjective Well-Being. Journal of the European Economic Association, 2(4), 696-719.

[37] de Tocqueville, Alexis (1848), "Democracy in America", reprinted in 1969 by Harper \& Row Publishers: New York.

[38] Tabellini, G. (2005). Culture and institutions: economic development in the regions of Europe. Working Paper No. 1492, CESifo.

[39] Thoenig, Matthias, Maystre, Nicolas, Olivier, Jacques and Thierry Verdier (2009). "Product-Based Cultural Change: Is the Village Global?", Working Paper, University of Geneva. 


\section{Appendix (Not Intended For Publication)}

This appendix provides descriptive statistics on all variables used in estimating model 3. All tables follow the same template. Columns 1-3 show means for all, job seekers in Latin regions, and job seekers in German speaking regions. Columns 4-6 show the language region difference in means, the language border difference in means, and the language border difference within bilingual regions. Columns 4-6 therefore allow assessing to what extent background characteristics are balanced.

Table 12 shows background information for individual characteristics (qualification, sector of last job, difficulty of placement, mobility, age, earnings, family characteristics and native language).

Table 12: Summary statistics: Individual characteristics
$(1)$
$(2)$
(3)
$(4)$
$(5)$
(6)

All Latin German Difference Difference at border

All Bilingual cantons

\begin{tabular}{|c|c|c|c|c|c|c|}
\hline \multicolumn{7}{|c|}{ Qualification } \\
\hline$\%$ low qualification & .08 & .09 & .08 & $.01 * * *$ & .01 & .00 \\
\hline$\%$ medium qualification & .10 & .10 & .10 & $.00^{* *}$ & $-.03^{* *}$ & $-.03^{* *}$ \\
\hline$\%$ high qualification & .82 & .81 & .82 & $-.01^{* * *}$ & .02 & .02 \\
\hline \multicolumn{7}{|c|}{ Sector of last job } \\
\hline$\%$ agrar & .03 & .03 & .02 & $.01^{* * *}$ & $.02^{* * *}$ & $.02^{* *}$ \\
\hline$\%$ construction & .11 & .11 & .10 & $.00 * * *$ & $-.04^{*}$ & $-.05^{*}$ \\
\hline$\%$ manufacturing & .17 & .15 & .18 & $-.03^{* * *}$ & $.05^{* * *}$ & $.05^{* *}$ \\
\hline$\%$ services & .49 & .48 & .50 & $-.03^{* * *}$ & .01 & .03 \\
\hline$\%$ tourism & .06 & .07 & .06 & $.01 * * *$ & -.01 & $.03^{* *}$ \\
\hline$\%$ other sector & .08 & .11 & .07 & $.04^{* * *}$ & $.02^{* *}$ & .01 \\
\hline \multicolumn{7}{|c|}{ Difficulty of placement (caseworker assessment) } \\
\hline$\%$ easy to place & .20 & .23 & .19 & $.05^{* * *}$ & $.13^{* * *}$ & $.07^{* * *}$ \\
\hline$\%$ medium to place & .64 & .64 & .63 & .00 & $-.10^{* * *}$ & .02 \\
\hline$\%$ hard to place & .15 & .11 & .17 & $-.05^{* * *}$ & $-.04^{* * *}$ & $-.09^{* * *}$ \\
\hline \multicolumn{7}{|c|}{ Mobility } \\
\hline$\%$ no mobility & .03 & .11 & .00 & $.11^{* * *}$ & $.00^{*}$ & .00 \\
\hline$\%$ daily mobility & .89 & .76 & .94 & $-.18^{* * *}$ & $-.05^{* * *}$ & $-.08^{* * *}$ \\
\hline$\%$ mobility: parts of $\mathrm{CH}$ & .04 & .06 & .02 & $.04 * * *$ & $.04^{* * *}$ & $.05^{* * *}$ \\
\hline \% mobility: whole $\mathrm{CH}$ & .03 & .04 & .02 & $.02^{* * *}$ & .00 & $.02^{*}$ \\
\hline$\%$ mobility: abroad & .02 & .03 & .01 & $.02^{* * *}$ & .00 & .01 \\
\hline \multicolumn{7}{|c|}{ Age and Earnings } \\
\hline Age & 38.49 & 37.66 & 38.70 & $-1.04^{* * *}$ & .10 & -.11 \\
\hline Log insured earnings & 8.49 & 8.42 & 8.51 & $-.09^{* * *}$ & $-.08^{* * *}$ & $-.08^{* * *}$ \\
\hline
\end{tabular}




\section{Family characteristics}

\begin{tabular}{lcccccc} 
No. of dependents & .96 & 1.01 & .94 & $.07^{* * *}$ & $.12^{* *}$ & .07 \\
\% single & .51 & .50 & .52 & $-.02^{* * *}$ & $-.04^{* *}$ & -.02 \\
\% married & .37 & .40 & .36 & $.03^{* * *}$ & .03 & .01 \\
\% divorced & .11 & .10 & .11 & $-.01^{* * *}$ & .01 & .01 \\
\% widowed & .00 & .00 & .00 & .00 & -.00 & .00 \\
& \multicolumn{7}{c}{ Mother tongue } \\
\% German native language & .69 & .05 & .97 & $-.92^{* * *}$ & $-.83^{* * *}$ & $-.72^{* * *}$ \\
\% Latin native language & .31 & .95 & .03 & $.92^{* * *}$ & $.83^{* * *}$ & $.72^{* * *}$ \\
\hline
\end{tabular}

Notes: Latin = majority in community speaks French, Italian or Romansh. Difference at the border is estimated using linear specifications. Source: Data from Unemployment Register 1998-2003, Swiss Census 2000, Federal Statistical Office (FSO), CH-2010 Neuchatel.

The results suggest that individual qualification levels do not differ significantly at the language border. It seems however, that on the Latin side of the border significantly more people work in the construction and manufacturing sector and less in the services sector than on the German side. This difference in sectoral composition of the unemployment pool could explain parts of the persistently higher unemployment duration. Note also, that people seem to be slightly more mobile, that is willing to travel to other parts in Switzerland, on the Latin speaking side. This enforces the conclusion that we would rather expect shorter than longer unemployment durations on the Latin side of the language border. Contrasting individuals within bilingual cantons reduces the pre-existing differences considerably.

Tables 13 and 14 summarize differences in community characteristics (educational, sectoral and religious structure as well as dimension and agglomeration status) and labor demand characteristics (growth in jobs and firms, vacancies), respectively.

Table 13 shows minor but statistically significant differences in sectoral structure at the language border. These can be explanatory for the different sectoral structure in the unemployment pool. Religious structure and dimension of communities do also differ to a large extent at the language border. Again, going closer to the language border reduces the pre-existing differences in means considerably. Communities are also slightly smaller on the Latin side of the language border.

Looking at table 14 yields that especially the number of work places differ somewhat at the language border. Arguably, this reflects the fact that communities are smaller rather than weaker labor demand. Indeed, a more direct measure of labor demand - vacancies per employed person- does not show any significant differences at the language border. Moreover, the median wage paid to employed workers is somewhat lower on the Latin side than on the German side of the language border. This could, again, reflect the fact that communities are smaller on the Latin side of the border (absence of city wage premium). In sum, labor demand appears to be quite balanced at the language border. 
Table 13: Summary statistics: Community characteristics

\begin{tabular}{lcccccc}
\hline & $(1)$ & $(2)$ & $(3)$ & $(4)$ & $(5)$ & $(6)$ \\
& All & Latin & German & Difference & \multicolumn{2}{c}{$\begin{array}{c}\text { Difference at border } \\
\text { \%ll }\end{array}$} \\
& & & & & Bilingual cantons \\
\hline \% primary education & .18 & .19 & .18 & $.01^{* * *}$ & -.01 & .01 \\
\% secondary education & .73 & .70 & .74 & $-.03^{* * *}$ & -.02 & $-.03^{* *}$ \\
\% other education & .02 & .02 & .02 & $-.00^{* * *}$ & $-.00^{*}$ & -.00 \\
\% sector 1 & .02 & .02 & .02 & $-.00^{* *}$ & $.01^{* * *}$ & .01 \\
\% sector 2 & .12 & .09 & .13 & $-.04^{* * *}$ & -.01 & -.01 \\
\% sector 3 & .39 & .38 & .40 & $-.02^{* * *}$ & $-.04^{* * *}$ & -.02 \\
\% age 25-29 & .08 & .08 & .07 & $.00^{* * *}$ & $-.01^{* * *}$ & $-.01^{* *}$ \\
\% age 30-34 & .09 & .09 & .09 & $-.01^{* * *}$ & $-.01^{* * *}$ & $-.01^{* * *}$ \\
\% age 35-39 & .10 & .09 & .10 & $-.01^{* * *}$ & $-.01^{* * *}$ & $-.01^{* * *}$ \\
\% age 40-44 & .09 & .09 & .09 & $-.01^{* * *}$ & $-.00^{* *}$ & -.00 \\
\% age 45-49 & .09 & .08 & .09 & $-.00^{* * *}$ & .00 & .00 \\
\% age 50-54 & .09 & .09 & .09 & $.00^{* * *}$ & .00 & .00 \\
\% age 55-59 & .08 & .08 & .08 & $.00^{* * *}$ & $.00^{* *}$ & $.01^{* * *}$ \\
\% men & .46 & .45 & .47 & $-.02^{* * *}$ & -.00 & -.01 \\
\% catholics & .41 & .49 & .37 & $.12^{* * * *}$ & .04 & .03 \\
\% protestants & .39 & .29 & .44 & $-.15^{* * *}$ & $-.05^{*}$ & -.05 \\
\% other language & .01 & .01 & .01 & $-.00^{* * *}$ & -.00 & -.00 \\
Log no. of inhabitants & 8.91 & 8.58 & 9.05 & $-.47^{* * *}$ & -.46 & $-.67^{*}$ \\
\% agglomeration & .54 & .51 & .55 & $-.05^{* * *}$ & -.09 & $-.39^{* * *}$ \\
\hline
\end{tabular}

Notes: Latin = majority in community speaks French, Italian or Romansh. Difference at the border is estimated using linear specifications. Source: Data from Unemployment Register 1998-2003, Swiss Census 2000, Federal Statistical Office (FSO), CH-2010 Neuchatel.

A final candidate for explanation of differences in labor market performance between language regions is differing labor market policies.

There is some indication that sanction rates are higher in the German-speaking regions and that they discontinuously fall at the language border. Similarly, assignment rates to employment programs and subsidized jobs are somewhat higher on the German-speaking side as compared to the Latin-speaking side of the language border. In contrast, training programs are more heavily used on the Latin-speaking side. In sum, differences in ALMP-treatment intensities between language regions and at the language border could have some explanatory power in explaining the language barrier effect in unemployment durations. 
Table 14: Summary statistics: Labor demand

\begin{tabular}{lcccccc}
\hline & $(1)$ & $(2)$ & $(3)$ & $(4)$ & $(5)$ & $(6)$ \\
& All & Latin & German & Difference & \multicolumn{2}{c}{$\begin{array}{c}\text { Difference at border } \\
\text { All }\end{array}$} \\
& & & & & Bilingual cantons \\
\hline Log no. of work places & 6.42 & 6.16 & 6.53 & $-.37^{* * *}$ & -.51 & -.69 \\
$\%$ new jobs & .06 & .07 & .06 & $.01^{* * *}$ & .01 & -.00 \\
$\%$ new firms & .01 & .00 & .02 & $-.02^{* * *}$ & $-.02^{* *}$ & $-.02^{*}$ \\
Vacancies per employed & .13 & .14 & .12 & $.02^{* * *}$ & .01 & -.01 \\
Log median wage & 3.55 & 3.51 & 3.57 & $-.05^{* * *}$ & $-.08^{* * *}$ & $-.09^{* * *}$ \\
\hline
\end{tabular}

Notes: Latin $=$ majority in community speaks French, Italian or Romansh. Difference at the border is estimated using linear specifications. Source: Data from Unemployment Register 1998-2003, Swiss Census 2000, Federal Statistical Office (FSO), CH-2010 Neuchatel.

Table 15: Summary statistics: Active labor market policies

\begin{tabular}{|c|c|c|c|c|c|c|}
\hline & (1) & $(2)$ & $(3)$ & (4) & $(5)$ & $(6)$ \\
\hline & All & Latin & German & Difference & \multicolumn{2}{|c|}{ Difference at border } \\
\hline & & & & & All & Bilingual cantons \\
\hline$\%$ days in sanction & .06 & .04 & .07 & $-.03^{* * *}$ & $-.01 * * *$ & .00 \\
\hline$\%$ days in course & .12 & .12 & .12 & $-.00 * * *$ & $.03^{* * *}$ & $.05^{* * *}$ \\
\hline$\%$ days in employment program & .01 & .01 & .01 & $-.00 * * *$ & $-.00^{*}$ & -.00 \\
\hline$\%$ days in subsidized employment & .11 & .11 & .10 & $.01^{* * *}$ & -.00 & -.01 \\
\hline
\end{tabular}

Notes: Latin $=$ majority in community speaks French, Italian or Romansh. Difference at the border is estimated using linear specifications. Source: Data from Unemployment Register 1998-2003, Swiss Census 2000, Federal Statistical Office (FSO), CH-2010 Neuchatel. 